\title{
Combining resistivity and frequency domain electromagnetic methods to investigate submarine groundwater discharge in the littoral zone
}

\author{
Marieke Paepen $^{1}$, Daan Hanssens ${ }^{2}$, Philippe De Smedt ${ }^{2}$, Kristine Walraevens $^{1}$, and Thomas Hermans ${ }^{1}$ \\ ${ }^{1}$ Laboratory for Applied Geology and Hydrogeology, Department of Geology, \\ Ghent University, Krijgslaan 281-S8, Ghent, 9000, Belgium \\ ${ }^{2}$ Research Group Soil Spatial Inventory Techniques, Department of Environment, \\ Ghent University, Coupure links 653, Ghent, 9000, Belgium
}

Correspondence: Marieke Paepen (marieke.paepen@ugent.be)

Received: 10 October 2019 - Discussion started: 22 January 2020

Revised: 17 April 2020 - Accepted: 3 June 2020 - Published: 15 July 2020

\begin{abstract}
Submarine groundwater discharge (SGD) is an important gateway for nutrients and pollutants from land to sea. While understanding SGD is crucial for managing nearshore ecosystems and coastal freshwater reserves, studying this discharge is complicated by its occurrence at the limit between land and sea, a dynamic environment. This practical difficulty is exacerbated by the significant spatial and temporal variability. Therefore, to capture the magnitude of SGD, a variety of techniques and measurements, applied over multiple periods, is needed. Here, we combine several geophysical methods to detect zones of fresh submarine groundwater discharge (FSGD) in the intertidal zone, upper beach, dunes, and shallow coastal area. Both terrestrial electrical-resistivity tomography (ERT; roll-along) and marine continuous resistivity profiling (CRP) are used from the shallow continental shelf up to the dunes and combined with frequency domain electromagnetic (FDEM) mapping in the intertidal zone. In particular, we apply an estimation of robust apparent electrical conductivity (rECa) from FDEM data to provide reliable lateral and vertical discrimination of FSGD zones. The study area is a very dynamic environment along the North Sea, characterized by semi-diurnal tides between 3 and $5 \mathrm{~m}$. CRP is usually applied in calmer conditions, but we prove that such surveys are possible and provide additional information to primarily land-bound ERT surveying. The 2D inversion models created from ERT and CRP data clearly indicate the presence of FSGD on the lower beach or below the low-water line. This discharge originates from a potable
\end{abstract}

freshwater lens below the dunes and flows underneath a thick saltwater lens, present from the dunes to the lower sandy beach, which is fully observed with ERT. Freshwater outflow intensity has increased since 1980, due to a decrease of groundwater pumping in the dunes. FDEM mapping at two different times reveals discharge at the same locations, clearly displays the lateral variation of the zone of discharge, and suggests that FSGD is stronger at the end of winter compared to the beginning of autumn. ERT, CRP, and FDEM are complementary tools in the investigation of SGD. They provide a high-resolution 3D image of the saltwater and freshwater distribution in the phreatic coastal aquifer over a relatively large area, both off- and onshore.

\section{Introduction}

The interface between land and sea is a complex environment, with groundwater discharging from the land to subterranean estuary and saltwater intruding into coastal aquifers (Duque et al., 2020). Submarine groundwater discharge (SGD) and seawater intrusion (SI) are complementary processes, both subjected to the balance between hydraulic and density gradients in groundwater and seawater (Taniguchi et al., 2002). SGD is a combination of fresh SGD (FSGD) and recirculated saline groundwater discharge (RSGD) (Taniguchi et al., 2002). It is driven by the terrestrial hydraulic gradient, water level differences at 
permeable barriers, wave set-up, tides, storm- or currentinduced pressure gradients, convection, seasonal freshwaterseawater interface movement, bioturbation, and geothermal heating (Taniguchi et al., 2002, 2019; Michael et al., 2005; Burnett et al., 2006). Its total flux is significant, since it occurs over large areas (Burnett et al., 2003), probably being more important to the oceanic budgets of nutrients, carbon, and metals than rivers (Moore, 2010).

FSGD can lead to eutrophication (e.g. Colman et al., 2004), blooms of harmful algae (e.g. Lapointe et al., 2005), and it can result in a significant loss of freshwater. RSGD can also have a significant impact on the dissolved nutrient input when it interacts with the sediment (Rodellas et al., 2018). On the other hand, SI threatens potable water in coastal zones. Therefore, understanding the dynamics of saltwater and freshwater is essential for the management of coastal freshwater reserves. However, the assessment of SGD is difficult because of spatial and temporal variability in flux (e.g. Burnett and Dulaiova, 2003; Michael et al., 2005).

Geophysical techniques can be used to delineate saltwater and freshwater in coastal environments, facilitating the detection of FSGD and SI. Electrical and electromagnetic methods are particularly suited for spatial and temporal salinity delineation in coastal environments given their sensitivity to (water) electrical conductivity. Below we give an overview of the methods used in coastal research.

Time domain electromagnetic (TDEM) methods are mostly used for 1D soundings in coastal studies, for instance to measure salinity onshore (e.g. Goldman et al., 1991) or offshore using a floating system (e.g. Goldman et al., 2004). Ground-based TDEM is time consuming and thus difficult to apply for 3D mapping. Similarly, frequency domain electromagnetics (FDEM), although mostly used onshore, can be used offshore as well, by towing a transmitter and receiver with a boat on the seafloor (Evans et al., 1999; Hoefel and Evans, 2001) or by keeping them above the water (Kinnear et al., 2013). FDEM is particularly suited for fast mapping of an area, but its depth resolution is limited and depends on the subsurface conductivity and the distance between the transmitting and receiving coils. The technique has been previously used to characterize pore water salinity in a coastal wetland (Greenwood et al., 2006) and to map saltwater intrusion on Long Reef Beach (Davies et al., 2015). It has also been combined with (continuous) vertical electrical and TDEM soundings to investigate the distribution of saltwater and freshwater on a sandy beach between Egmond aan Zee and Castricum aan Zee (Pauw, 2009), combined with $2 \mathrm{D}$ resistivity imaging to detect plumes of freshwater on a beach in northern Wales (Obikoya and Bennell, 2012), and combined with TDEM and onshore electrical resistivity tomography (ERT) to discriminate freshwater and saltwater in the Albufeira-Ribeira de Quarteira coastal aquifer system (Francés et al., 2015). However, when applying FDEM in saline environments, it is important to know that ground conductivity instruments designed to operate under low-induction-number (LIN) conditions (e.g. CMDMiniExplorer, DUALEM-421S, Geonics EM34, and Geonics EM31) provide apparent electrical conductivities (ECa) which are not valid in highly conductive environments (McNeill, 1980; Hanssens et al., 2019). This limitation is probably why FDEM has only rarely been applied in the intertidal zone and only the ECa values were used in the interpretation of these studies.

Both FDEM and TDEM methods are also available for airborne surveys, allowing for the expansion of coverage in coastal and tidal environments; see Siemon et al. (2009) and Viezzoli et al. (2012) for some examples. These surveys can be combined with for instance EM (electromagnetic; e.g. Paine, 2003) or ERT studies on land (e.g. Viezzoli et al., 2010; Goebel et al., 2019). However, airborne surveys are costly and often aim at large-scale structures, so they might lack resolution at shallow depth, which is crucial to image local FSGD.

Next to EM, ERT is another useful geophysical method in mapping coastal salinity. ERT allows for imaging the subsurface resistivity in $2 \mathrm{D}$ cross sections of $3 \mathrm{D}$, after the data are inverted. The depth of investigation and resolution of ERT are respectively proportional and inversely proportional to the electrode spacing but also depend on the distribution of the subsurface resistivity and the chosen electrode array (Dahlin and Zhou, 2004). The ERT cables and electrodes remain fixed during the measurement so that it can be used above the high-tide mark (e.g. Goebel et al., 2017) and in the intertidal zone to measure for instance the tidal effect on groundwater exchange (e.g. Dimova et al., 2012). Time-lapse ERT is popular for monitoring SI (e.g. de Franco et al., 2009; Ogilvy et al., 2009), including cross-hole ERT to increase resolution (e.g. Palacios et al., 2020).

Resistivity surveying can be extended to water bodies by burying cables or resting them on top of the sediments (marine electrical resistivity - MER; e.g. Swarzenski et al., 2006; Taniguchi et al., 2007; Swarzenski and Izbicki; 2009; Henderson et al., 2010). In the case of saline water, MER provides a better resolution, since the conductive water layer on top has less effect on the signal compared to continuous resistivity profiling (CRP), where the current has to pass the water layer before entering the sediment. In addition, MER allows for collecting reciprocal data to estimate the noise level. It is more time consuming but best suited for monitoring. In contrast, by using CRP, one can easily cover several kilometres per day. In order to compensate the effect of the water layer (between the streamer and sediment) during the inversion process, the bathymetry and water conductivity are measured at the same time. The resolution of the measurements depends on the electrode spacing, height of the waves, and boat speed. Most CRP studies found in the literature were carried out in quiet environments with limited tidal and wave activity such as Biscayne Bay (Swarzenski et al., 2004), Neuse River Bay (Cross et al., 2006), Florida Bay (Swarzenski et al., 2009), Manhasset Bay and North- 
port Harbor (Cross et al., 2012), Great South Bay (Cross et al., 2013), Jobos Bay in Puerto Rico (Day-Lewis et al., 2006), and the fringing reef of Santiago Island in the Philippines (Cardenas et al., 2010; Cantarero et al., 2019). These are sometimes combined with radon-222 (e.g. Swarzenski et al., 2004, 2009), MER (e.g. Swarzenski and Izbicki, 2009), seismics (e.g. Russoniello et al., 2013; Cross et al., 2014), EM logs in temporary boreholes (e.g. Krantz et al., 2004), or salinity measurements (Cardenas et al., 2010; Cantarero et al., 2019).

Most of the geophysical studies identified above do not bridge the gap between the land and marine realms. Offshore and onshore surveys are rather performed separately, especially if conditions are difficult, e.g. strong tidal and wave activity. Additionally, the spatial and temporal variability of FSGD make it more challenging. Onshore surveys alone are generally not sufficient to image the full extent of the FSGD zone, while offshore surveys miss the necessary connections with onshore freshwater aquifers. Similarly, while FDEM surveys allow for faster mapping at a higher resolution of the salinity than resistivity methods, they do not bring sufficient information on the vertical distribution of salinity.

In this paper, we combine for the first time ERT, CRP, and FDEM. The objective of the survey is to qualitatively map the lateral and vertical distribution of saltwater and freshwater and identify the FSGD zone underneath the nearshore continental shelf, intertidal zone, upper beach, and dunes, at the De Westhoek nature reserve, Belgium. ERT and CRP provide changes of the subsurface resistivity in $2 \mathrm{D}$ cross sections, while FDEM mapping with robust apparent electrical conductivity ( $\mathrm{rECa}$ ) provides additional information on lateral variations in the intertidal zone between parallel cross sections. The combination of CRP during high tide and land ERT collected at low tide ensures that FSGD and SI can be accurately imaged at the limit of the low-water line. Our case study demonstrates that only a combination of the proposed methods allows for fully characterizing the discharge zone in the target area. It also shows that CRP data can directly provide a reliable identification of the presence of fresher water, even in very dynamic environments with a large tidal range, and that FDEM monitoring can be used to quickly assess seasonal variations in FSGD in the intertidal zone.

\section{Study area}

The study site is located in the most western part of the $65 \mathrm{~km}$ long sandy coastline of Belgium, which is delimited by the North Sea in the north and a southwest-northeastoriented, semi-continuous dune belt in the south, which varies in width. These dunes are part of a long, narrow dune strip that runs from Calais, France, to northern Denmark. The Belgian coastal dune belt is around $2 \mathrm{~km}$ wide at De Westhoek - an extensive Flemish nature reserve and European Natura 2000 area - which is located between the
Belgian-French border and the city of De Panne (Fig. 1). A groundwater extraction site is situated in the dunes, exploited by Intercommunale Waterleidingsmaatschappij van VeurneAmbacht (IWVA). Potable groundwater has been pumped there since 1967.

A low-lying polder area borders the dunes in the south. The shore in the north is tidal dominated (semi-diurnal), with a tidal range of over $5 \mathrm{~m}$ at spring tide and approximately $3 \mathrm{~m}$ at neap tide. The beach is relatively flat with an average slope of $1.1 \%$ (Lebbe, 1981). The shore morphology, tidal range, and permeability of the phreatic aquifer determine the presence of a saltwater lens under the shore; saltwater can infiltrate on the backshore during high and spring tide and discharges on the foreshore and/or seabed (Vandenbohede and Lebbe, 2006).

The sandy aquifer is around $30 \mathrm{~m}$ thick at the shore and up to $50 \mathrm{~m}$ in the dunes (due to a recent aeolian sand cover) and bounded by Late Eocene heavy marine clays of the Kortrijk Formation, which are considered impermeable. The aquifer is relatively homogeneous at the Belgian-French border; the upper part is fine medium sand, and the lower part has more coarse and medium sands. It becomes more heterogeneous towards the east, with the local occurrence of clayey-silty fine-sand lenses (e.g. Lebbe, 1978, 1999). For instance, a clay lens occurs between -5 and -10 mTAW (compared to the mean sea level at low tide in Ostend, which is the Belgian reference level) under the upper beach and fore dunes in the east of the study zone (Vandenbohede et al., 2008b; Hermans et al., 2012).

Freshwater recharges in the dunes, forming a large freshwater lens underneath. Part of this freshwater flows underneath the large saltwater lens, forming a freshwater tongue, discharging into the North Sea around the low-water line (Vandenbohede and Lebbe, 2006). The potable water is of high value in the coastal region, since saltwater and brackish water are often found at shallow depth (i.e. the beach and polder area; De Breuck et al., 1974; Delsman et al., 2019). The scarcity of freshwater in the region and the high demand of drinking supplies, especially in summer (due to coastal tourism), make a comprehensive understanding of the hydrogeological system important for the sustainable management of the phreatic groundwater reserves.

In the past, the migration of fresh groundwater towards the sea has been observed at De Westhoek by electrical well logging in 1980 (Lebbe, 1981, 1999) and temperature measurements (Vandenbohede and Lebbe, 2011). Several hydrogeological and groundwater flow models have been developed showing sensitive parameters and the past, present, and future evolution of the freshwater tongue (Lebbe, 1983, 1984, 1999; Lebbe and Walraevens, 1988; Van Camp and Walraevens, 2004; Vandenbohede and Lebbe, 2006, 2007; Vandenbohede et al., 2008a). However, these models are 2D cross sections and do not account for the lateral variations along the coastline. The latter can be revealed by geophysics. In addition, conditions have changed over the years 


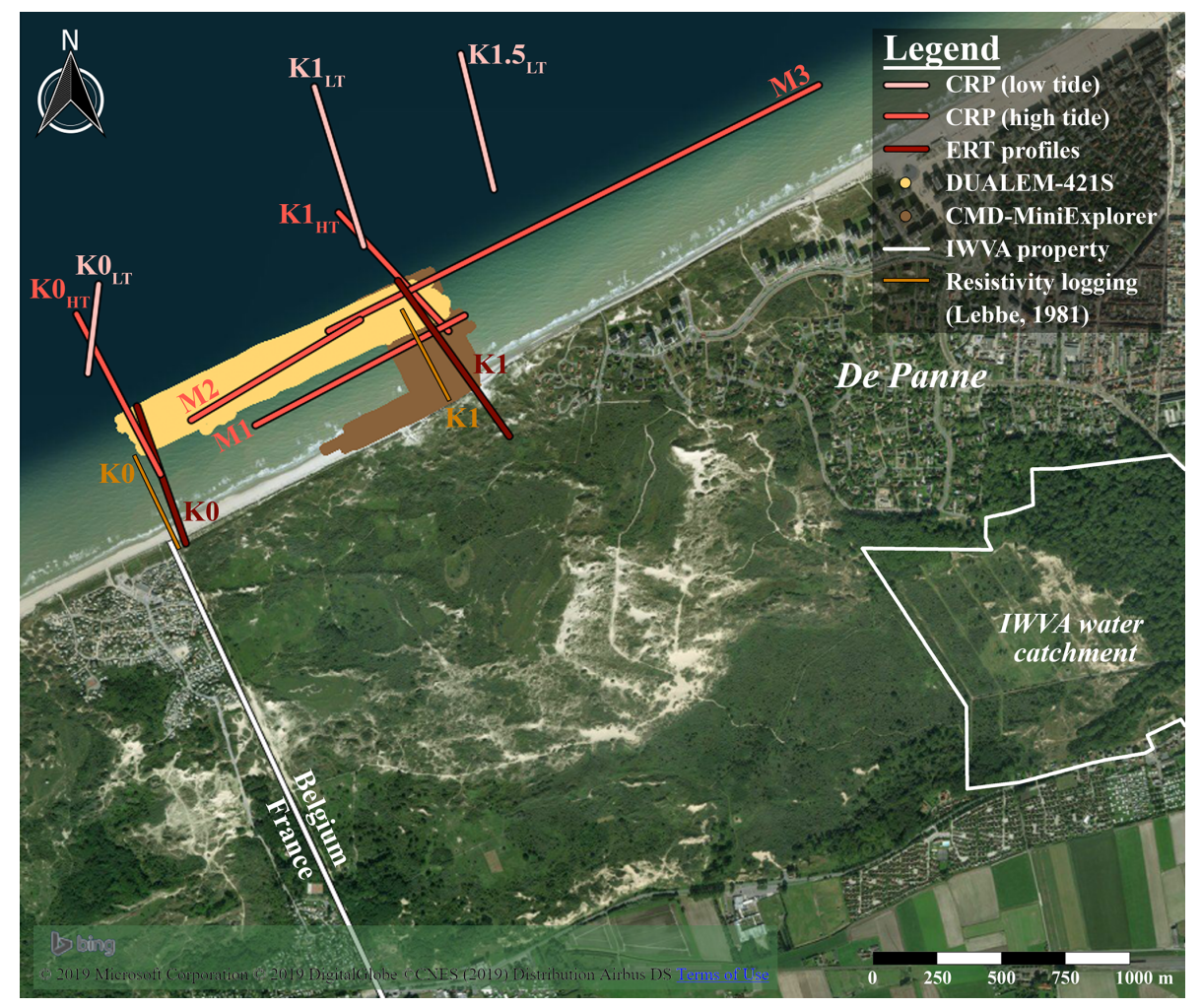

Figure 1. The De Westhoek study area, between the Belgian-French border and the city of De Panne. With the location of the ERT and CRP profiles, zones of FDEM mapping, resistivity logging profiles of Lebbe (1981), and IWVA groundwater extraction site. (C) Microsoft Corporation, DigitalGlobe, and CNES, 2019.

since the IWVA started a decrease of the exploitation rate at De Westhoek in the 1990s. Nowadays, the pumping rate (approximately $3.2 \times 10^{5} \mathrm{~m}^{3}$ in 2018) is much smaller compared to the $1980 \mathrm{~s}$, when pumping rates were between 1.5 and $2.2 \times 10^{6} \mathrm{~m}^{3} \mathrm{yr}^{-1}$.

\section{Methodology}

\subsection{Electrical resistivity}

\subsubsection{ERT on land}

\section{Data acquisition}

The ABEM Terrameter LS with 64 electrodes was used for the ERT survey on land. Data acquisition took place on multiple days - 7 March (one profile $1 \mathrm{~km}$ east of the BelgianFrench border, K1) and 11 October 2018 (one profile at the border, K0). Measurements started during the lowest tide, allowing to measure a wide zone, with the roll-along technique. Using this method, the Terrameter is placed between electrodes 32 and 33. After measuring, it is shifted by 16 or 32 electrodes while new electrodes are positioned at the end of the profile so that the device is back in the middle of the array to perform new measurements. This procedure can be repeated numerous times to obtain very long ERT profiles while maintaining relatively homogeneous lateral sensitivity. It also allows for maintaining all the measuring electrodes above the current tide level. Combined with a spacing of $5 \mathrm{~m}$ between the electrodes, profiles of up to $625 \mathrm{~m}$ long were obtained. The multiple-gradient array configuration was chosen for its relatively fast data acquisition speed, which is critical in tidal-dominated environments, and its good compromise between signal-to-noise ratio and resolution (e.g. Dahlin and Zhou, 2004, 2006).

\subsubsection{Marine CRP}

\section{Data acquisition}

For the marine survey, direct-current CRP is preferred over the MER mode (in which electrodes are buried or rest on the seabed), since data collection is easier and faster. The use of CRP in a very dynamic environment, such as the North Sea (semi-diurnal tides - tidal range between approximately 3 and $5.3 \mathrm{~m}-$ and often relatively strong waves), is not common. Measurements were only performed under relatively calm weather conditions, with a maximum wave height of around $1 \mathrm{~m}$ and maximum wind speed of $5.5 \mathrm{~m} \mathrm{~s}^{-1}$. CRP is performed nearshore, both during high and low tide. The for- 
mer ensures some overlapping with ERT on land, and the latter improves the resolution offshore, since the seawater layer is thinner in the low-tide conditions.

Water-borne data were collected at high tide during a single day in 2018 (30 May). A total of two perpendicular and three parallel profiles were obtained. The Syscal Pro Deep Marine (IRIS Instruments) was used, combined with a $195 \mathrm{~m}$ long floating streamer of 13 graphite takeouts - 2 fixed current electrodes and 11 potential electrodes - spaced at a $15 \mathrm{~m}$ interval. Using a reciprocal Wenner-Schlumberger configuration, with the current electrodes in the middle of the set-up, the simultaneous collection of 10 potentials was obtained for each current transmission (of 35 to $37 \mathrm{~A}$ ). The streamer was towed at a relatively constant speed (around $3.5 \mathrm{~km} \mathrm{~h}^{-1}$ ) by a small rigid inflatable boat from the Flanders Marine Institute (VLIZ), which collected data continuously. In order to correct for the influence of the highly conductive seawater layer on the signal, a Garmin GPSMAP 188 Sounder system was directly connected to the Syscal unit (obtaining coordinates and water depth), and seawater conductivity was separately recorded using a CTD (conductivity-temperaturedepth) diver.

An additional marine survey was carried out on 22 May 2019, allowing to measure three perpendicular profiles during low tide in front of De Westhoek. Again, the Syscal was used with the same set-up but with a cable of $130 \mathrm{~m}$. The 13 electrodes were spaced at $10 \mathrm{~m}$, allowing for a better resolution yet sufficient penetration into the seabed.

\section{Pre-processing}

In a first step, the raw marine data were checked, showing the general trend in apparent resistivity. For the perpendicular high-tide profiles, e.g. $\mathrm{K} 0_{\mathrm{HT}}$ (Fig. 2), an increase in resistivity is observed towards the beach. This is not only caused by the decreasing thickness of the seawater layer - since other perpendicular CRP profiles made at Wenduine, Belgium, (where possibly no or much less FSGD occurs; Fig. 2) barely show this trend towards the land - but mainly due to the outflow of fresh or brackish groundwater. The raw data also display two bad acquisition channels (rho 6 and rho 7, Fig. 2) in all marine profiles (2018) caused by one damaged electrode. These channels were removed from the datasets, reducing the sensitivity of the inversion models.

The bathymetry was filtered to remove the noise effect caused by the waves, by averaging the data. The echosounder measurements of 2018 also comprise multiples. These were calibrated with the known shore topography.

\subsubsection{Processing}

Both marine and land ERT data were inverted using the RES2DINVx32 ver. 3.71.118 software. For marine data, potentials were continuously measured, which prevents the estimation of the error through stacking or reciprocal measure- ments. For land ERT, reciprocals could not be collected because of time constraints related to the rising tide. The repeatability error was low, indicating data of good quality. For the CRP inversion, the water layer was included using the measured seawater conductivity (approximately $5 \mathrm{~S} \mathrm{~m}^{-1}$ ) and bathymetry (Loke, 2011). Note that the conductivity of the water layer is introduced as a soft constraint and is not fixed during the inversion. This option was used to prevent the creation of artefacts of inversion, as these can occur when (potentially erroneous) strong constraints are introduced (Henderson et al., 2010; Caterina et al., 2014).

Bad data points were filtered after a first inversion based on the root mean square error $\left(E_{\mathrm{RMS}}>100 \%\right)$. A robust inversion was carried out, using the floating-electrode-survey option for the marine profiles. Given the absence of robust error estimates, we relied on the convergence criterion typically used for ERT to stop the inversion process (decrease of $E_{\mathrm{RMS}}$ lower than $0.1 \%$ between two iterations). The mean absolute error of all inverted models lies below $2.8 \%$.

\subsubsection{Inversion model appraisal}

The resolution of resistivity profiles quickly decreases with depth. This is particularly true for marine profiles, as a large portion of the current directly flows in the water layer. The inversion of marine data is thus subject to large uncertainty, and the quantitative interpretation of inversion results might be especially difficult (Day-Lewis et al., 2006). In our case, we are mostly interested in the relative variation of resistivity indicating the presence of fresher water. To obtain information on how much the model is influenced by the inversion parameters (bathymetry, starting model, etc.) and if reliable resistivity variations are mapped, we propose an approach based on the two-sided difference developed by Oldenburg and $\mathrm{Li}$ (1999) for estimating the depth-of-investigation (DOI) index. The DOI is an image appraisal tool which is often used to indicate which portions of the inversion model can be interpreted. It is calculated based on two additional inversions $\left(\rho_{\text {inv, } 1}\right.$ and $\left.\rho_{\text {inv }, 2}\right)$ using the same dataset but for which 0.1 and 10 times the reference resistivity $\left(\rho_{\text {ref,1 }}\right.$ and $\left.\rho_{\text {ref,2 }}\right)$ are imposed as a reference model:

DOI $=\left|\frac{\log \rho_{\text {inv }, 1}-\log \rho_{\text {inv }, 2}}{\log \rho_{\text {ref, } 1}-\log \rho_{\text {ref }, 2}}\right|$.

A low DOI value is obtained when resistivity structures in the model are driven by the data and not by the inversion process which is influenced by the reference model. Although a threshold between 0.1 and 0.2 on the DOI value is often used to delimit reliable zones of the image, this choice is subjective (Caterina et al., 2013). In addition, the DOI is directly sensitive to the absolute value of resistivity and can thus yield high values even for consistently resistive or conductive structures. Therefore, we do not interpret the absolute DOI value itself, even though it is very low throughout most inversion models but interpret it qualitatively with the 

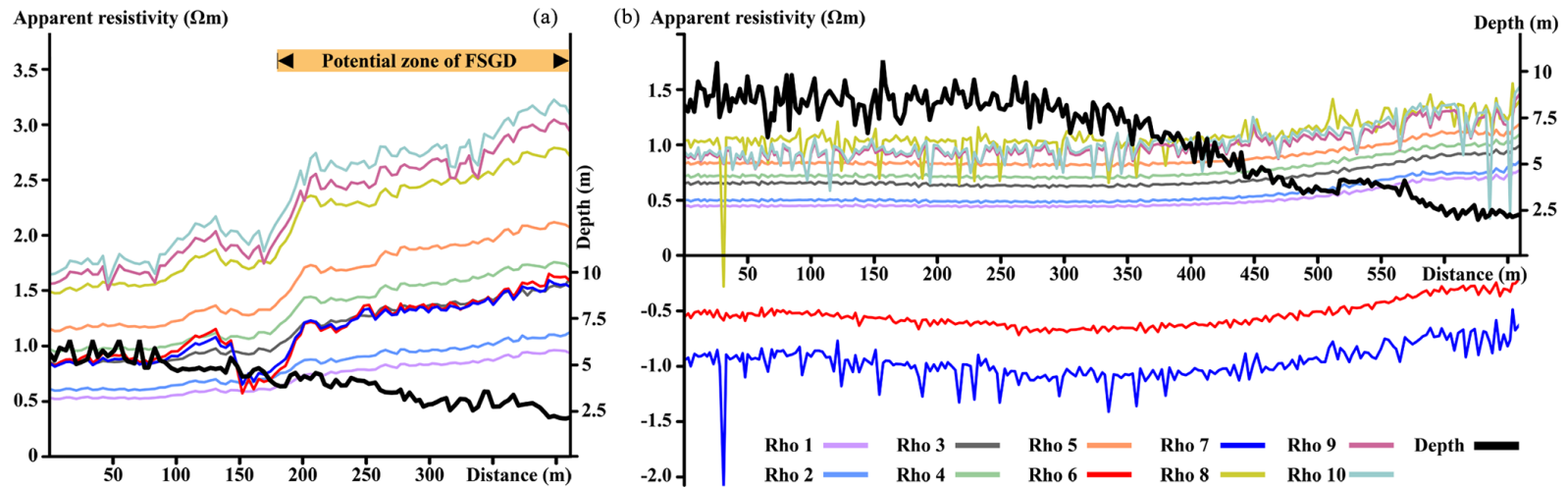

Figure 2. Raw resistivity data plots versus bathymetry. (a) Profile $\mathrm{K}_{\mathrm{HT}}$ : strong resistivity increase towards the beach, mainly due to SGD. (b) A perpendicular profile in front of the dunes of Wenduine, Belgium, where resistivity increases only slightly with decreasing water depth.

three respective inversions. We assume that we can make a robust qualitative interpretation of the inversion model when all three inverted models show similar resistivity patterns. We are more careful in the evaluation if the models do not agree on the resistivity of certain zones. For marine data, the DOI is especially influenced by the thickness of the seawater layer (bathymetry), which has a large effect on the calculated value.

\subsection{Electromagnetic}

\subsubsection{Data acquisition}

Two different FDEM devices were used at De Westhoek. Both have a short acquisition time and are relatively easy to use in the intertidal zone. The DUALEM-421S has the advantage of a larger investigation depth compared to the CMD-MiniExplorer, which only gives information of the upper $2 \mathrm{~m}$.

The CMD-MiniExplorer (GF Instruments, s.r.o., Czech Republic) is a portable multi-depth FDEM device which measures apparent electrical conductivities $\left(\mathrm{mS} \mathrm{m}^{-1}\right)$. It was used for mapping on 23 February 2018. The unit is relatively small and, therefore, easy to use. The entire device is operated by one person, who carries the $1.62 \mathrm{~m}$ long probe together with a Trimble GPS (Trimble Navigation Ltd., Sunnyvale, California, USA). The system operates at $30 \mathrm{kHz}$ and contains three different receiver coils - dipole distances of $0.32 \mathrm{~m}$ (CMD1), $0.71 \mathrm{~m}$ (CMD2), and $1.18 \mathrm{~m}$ (CMD3). The horizontal-coplanar (HCP) configuration was used, giving a cumulative sensitivity of $0.5,1.0$, and $1.8 \mathrm{~m}$, respectively, under LIN (Callegary et al., 2007).

Multiple-receiver FDEM data were recorded using a DUALEM-421S instrument (DUALEM Inc., Milton, Canada) mounted on a sled and towed by an all-terrain vehicle on 27 and 28 September 2018, after a very warm and dry summer. The device worked in HCP mode, which resulted in three HCP configurations with a coil spacing of 1 (HCP1), 2 (HCP2), and $4 \mathrm{~m}$ (HCP4) and three perpendicular (PRP) configurations with a coil spacing of 1.1 (PRP1), 2.1 (PRP2), and $4.1 \mathrm{~m}$ (PRP4). Therefore, six different volume-related apparent conductivities are recorded simultaneously. The depths at which the signal sensitivities are highest is ambiguous, since these depend on the specific subsurface conductivity distribution. The approximate depths of investigation provided by the six coil configurations are 0.5 (PRP1), 1 (PRP2), 1.5 (HCP1), 2 (PRP4), 3 (HCP2), and $6 \mathrm{~m}$ (HCP4), but they have no physical meaning in this highly conductive environment. To allow for a straightforward comparison between datasets obtained with different coil configurations and instruments, these are here referred to as pseudodepths. The instrument's operating frequency was $9 \mathrm{kHz}$, and elevation above the ground was $0.195 \mathrm{~m}$. The sampling frequency was $8 \mathrm{~Hz}$ at an acquisition speed of approximately $8 \mathrm{~km} \mathrm{~h}^{-1}$, rendering an in-line sampling spacing of approximately $0.25 \mathrm{~m}$. Survey lines were repeated in parallel lines at a spacing of approximately $5.5 \mathrm{~m}$. Geographic coordinates were logged using a Trimble R10 GNSS (global-navigationsatellite-system) system (Trimble Navigation Ltd., Sunnyvale, California, USA).

\subsubsection{Processing}

Basic processing of the DUALEM measurements was done following Delefortrie et al. (2014, 2015). The linear relation between the quadrature-phase (QP) component of the electromagnetic field and the LIN ECa (McNeill, 1980) - used in most commercially available FDEM equipment - is not valid in highly conductive environments, as it generally underestimates electrical conductivity (Fig. 3, left). Different from most studies, we converted the LIN ECa data to robust $\mathrm{ECa}(\mathrm{rECa})$, enabling qualitative FDEM data interpretation in a highly conductive environment. We follow the non-linear approach of Hanssens et al. (2019), in which $\mathrm{rECa}$ $\left(\mathrm{mS} \mathrm{m}^{-1}\right)$ data are calculated from the QP data to accurately estimate ECa at higher induction numbers (Fig. 3, right). Ultimately, the data were interpolated in the software applica- 
tion Surfer 13 to a $2 \mathrm{~m}$ by $2 \mathrm{~m}$ grid, via natural neighbour interpolation.

\subsection{Interpretation}

The inversion of resistivity data acts as a filter which tends to blur the obtained image: the inverted resistivity is only an estimation of the true resistivity. For this reason, it is difficult to directly relate an inverted-resistivity value to a specific value of the salinity or total dissolved solid (TDS) content. However, in this case, we have two well-identified extremes (freshwater in the dunes and seawater), together with a petrophysical model developed by Lebbe (1978, 1981, 1999) for the western Belgian coastal plain, allowing for a semi-quantitative interpretation of resistivity. Archie's law (Archie, 1942) is used to estimate the pore water resistivity $\left(\rho_{\mathrm{w}}\right)$ :

$\rho_{\mathrm{w}}=\frac{\rho_{\mathrm{b}}}{F}$.

For sandy sediments at De Westhoek, Lebbe (1981) estimated the formation factor $(F)$ to be 3.2. The bulk resistivity $\left(\rho_{\mathrm{b}}\right)$, is deduced from ERT and CRP profiling and FDEM mapping (given the scale of measurement, we assume that the rECa value can approximate $\rho_{\mathrm{b}}$ ). Here, we propose a semi-quantitative interpretation in salinity classes based on relative variations in resistivity (and conductivity). Due to measurement errors, resolution, and inversion constraints, deducing the effective TDS would only be possible with a specific calibration of geophysical measurements based on ground truth data. We distinguish three main water quality classes (saltwater, brackish water, and freshwater) to interpret the geophysical data in the specific study area (De Moor and De Breuck, 1969).

\section{Results and discussion}

In the following paragraphs, we present the data and results for each of the used methods, starting with FDEM, then land and marine resistivity measurements. In the east of the study area, FDEM data were acquired during two different seasons, allowing for an investigation of seasonal variability of the fresh-groundwater discharge. By comparing our results to previous observations, we can see how the freshwatersaltwater distribution has changed since the 1980s, due to a decrease of pumping in the nearby groundwater extraction facility. In the following, we will use a unique colour scale to describe the results in all figures (except in Fig. 4): freshwater occurs in zones with a resistivity higher than approximately $20 \Omega \mathrm{m}$ (blue); saltwater has a resistivity lower than roughly $2.5 \Omega \mathrm{m}$ (red); and brackish water leads to intermediate resistivities (light brown to light blue). In the case of the Belgian coast, the strong tides play a role in allowing saltwater to penetrate in the shallow sediment, and making the detection of FSGD - based on resistivity and conductivity - more difficult. The discharge zone will thus not be necessarily characterized by freshwater but rather by brackish water.

\subsection{FDEM}

We started our investigation with the CMD-MiniExplorer mapping at the location of one of the profiles of Lebbe (1981), K1, located $1 \mathrm{~km}$ east of the Belgian-French border. The CMD-MiniExplorer mapping (Fig. 3, right, and Fig. 4A) identifies the presence of FSGD close to the lowwater line, at K1, indicated by a decrease in the electrical conductivity. The FDEM data clearly demonstrate a zone over $100 \mathrm{~m}$ wide. The outflowing water varies from very brackish water to moderate saltwater; the conductivity is roughly between 350 and $650 \mathrm{mS} \mathrm{m}^{-1}$, due to a mixture of discharging fresh groundwater and seawater that infiltrated on the beach during high tide.

To investigate lateral variation between the western and eastern part of the study area, the intertidal zone was also mapped with the DUALEM at the vicinity of the low-water line. This map clearly demonstrates a northward shift of the zone of discharge from the east to the west (Fig. 4B-D). From approximately $300 \mathrm{~m}$ east of the border, the discharge zone is no longer visible from the EM data, since the discharge is located below the low-water line. The DUALEM was dragged on the beach in a sled, making the quality of the data higher compared to the MiniExplorer, which was carried by hand, making it difficult to maintain a constant height above the surface during mapping. The water conductivity, obtained with the DUALEM-421S, in the discharge zone corresponds to a brackish-water type, confirming the mixing of freshwater with salty water.

\subsection{Land ERT}

Interpreted on its own, the conductivity variations observed with FDEM could be related to lithological heterogeneities or the presence of near-surface features. Therefore, long land ERT profiles (Fig. 5) covering the entire zone between the low-water line and the dune area were collected. In the east (Fig. 5, K1), we identify the freshwater aquifer located in the dune area. The brackish water observed at -10 mTAW corresponds to remnants of seawater infiltration during the flooding of an artificial tidal inlet, which started in 2004 and ended a few years ago. The downward movement of the denser seawater is hindered by the presence of a local clay lens, a process that was closely monitored in previous studies (Vandenbohede et al., 2008b; Hermans et al., 2012). Along this profile, there is a large saltwater lens on the beach. Underneath, freshwater is flowing from the dunes towards the North Sea. The freshwater mixes with the saltwater, leading to the discharge of saltwater to brackish water during low tide on the lower beach. This is clearly visible on the land profile, close to the low-water line, where fresher water is seen near the 


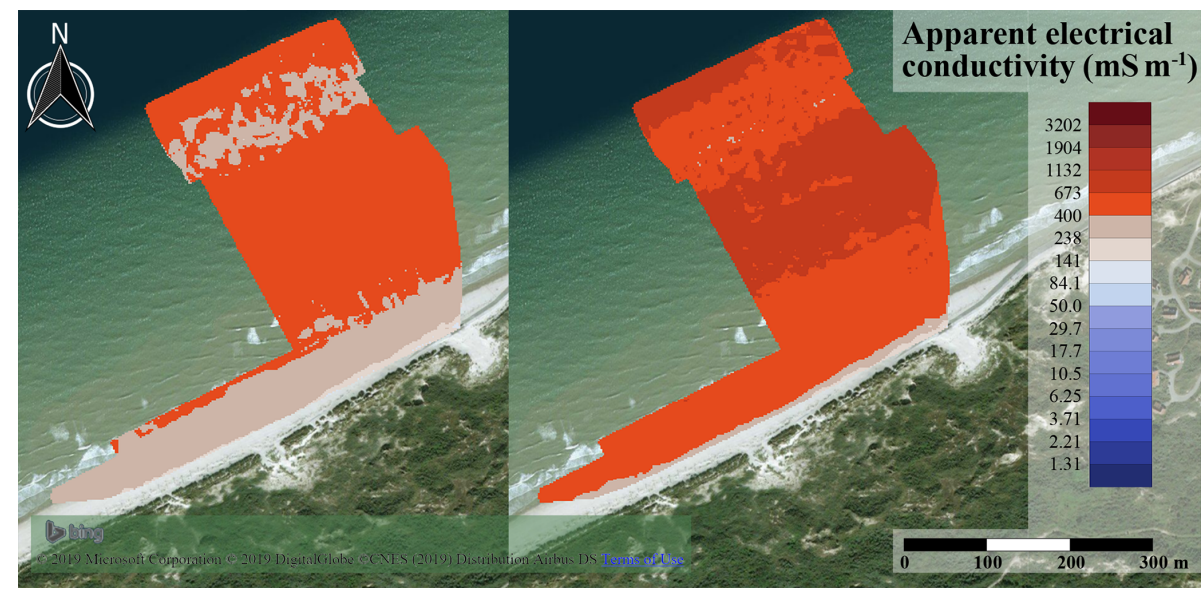

Figure 3. The CMD-MiniExplorer ECa mapping (left panel) versus rECa (right panel), both with CMD3, and a pseudodepth of approximately 1.8 m (23 February 2018). (C) Microsoft Corporation, DigitalGlobe, and CNES, 2019.

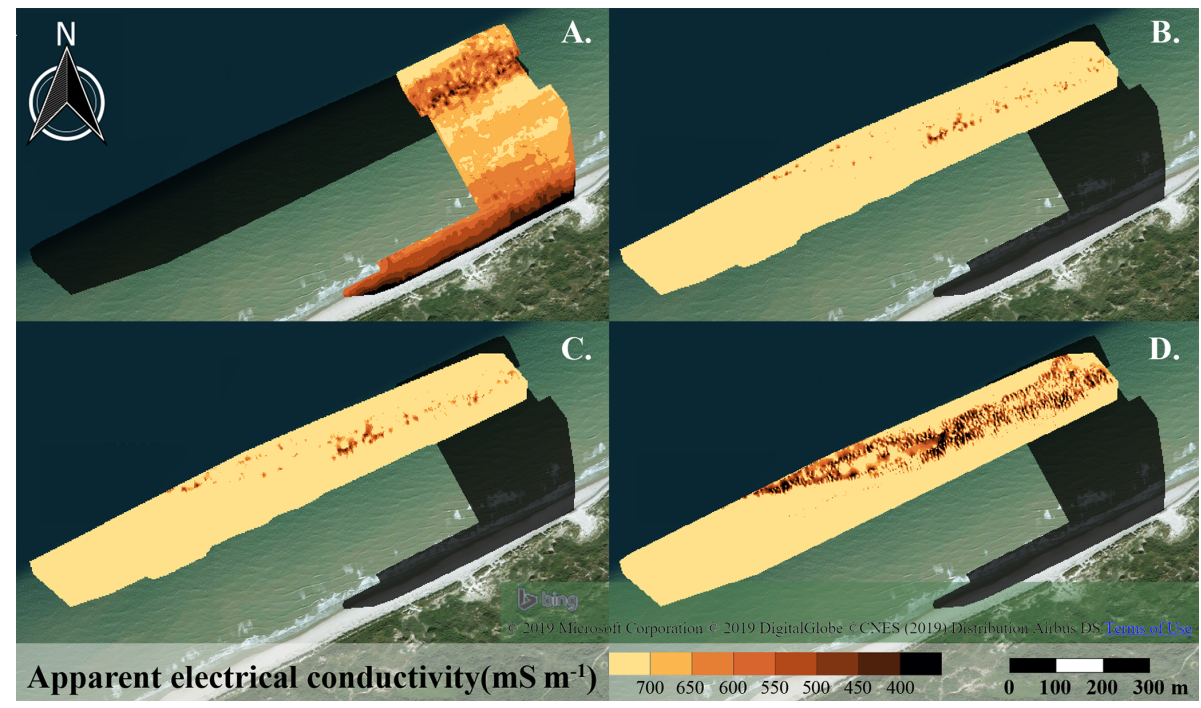

Figure 4. FDEM data. (A.) rECa (CMD-MiniExplorer) using CMD3, with a pseudodepth of approximately $1.8 \mathrm{~m}$ (23 February 2018 ). (B.-D.) rECa (DUALEM-421S) using the HCP1, PRP4, and HCP4 configurations, respectively, providing pseudodepths of 1.5, 2, and $6 \mathrm{~m}$ (27-28 September 2018). Note that another colour scale is used compared to the other figures. (C) Microsoft Corporation, DigitalGlobe, and CNES, 2019.

surface, which corresponds to the zone identified by FDEM measurements.

In the centre of profile K1 (Fig. 5), the groundwater appears to be brackish. Here, the thickness of the saltwater lens is at its maximum $(15 \mathrm{~m})$, while the bottom boundary of the aquifer (thick clay layer) is located between -25 and -30 mTAW. The lower resistivity is likely a result from the smoothness constraint inversion combined with the lower resolution at depth as the more resistive freshwater is bounded by two conductive layers, leading to a lower inverted resistivity (Hermans and Paepen, 2020).

There is a similar situation $1 \mathrm{~km}$ to the west, at the Belgian-French border (Fig. 5, K0), where freshwater moves underneath a saltwater lens from the dunes towards the sea. Nevertheless, a striking difference on this profile is the absence of freshwater flowing upwards and discharging on the lower beach. The saltwater lens, although becoming thinner towards the low-water line, remains continuous. At the seaside of the profile, the underlying water is identified as fresh, whereas it seems more brackish towards the dunes. This is probably related to the higher resolution at depth when the conductive salt layer is thinner and not due to an actual variation in salinity. On this profile, the clay layer (Kortrijk Formation) underlying the coastal aquifer is detected around -35 mTAW. The ERT data at the border gives the natural distribution of saltwater and freshwater, since the groundwater 


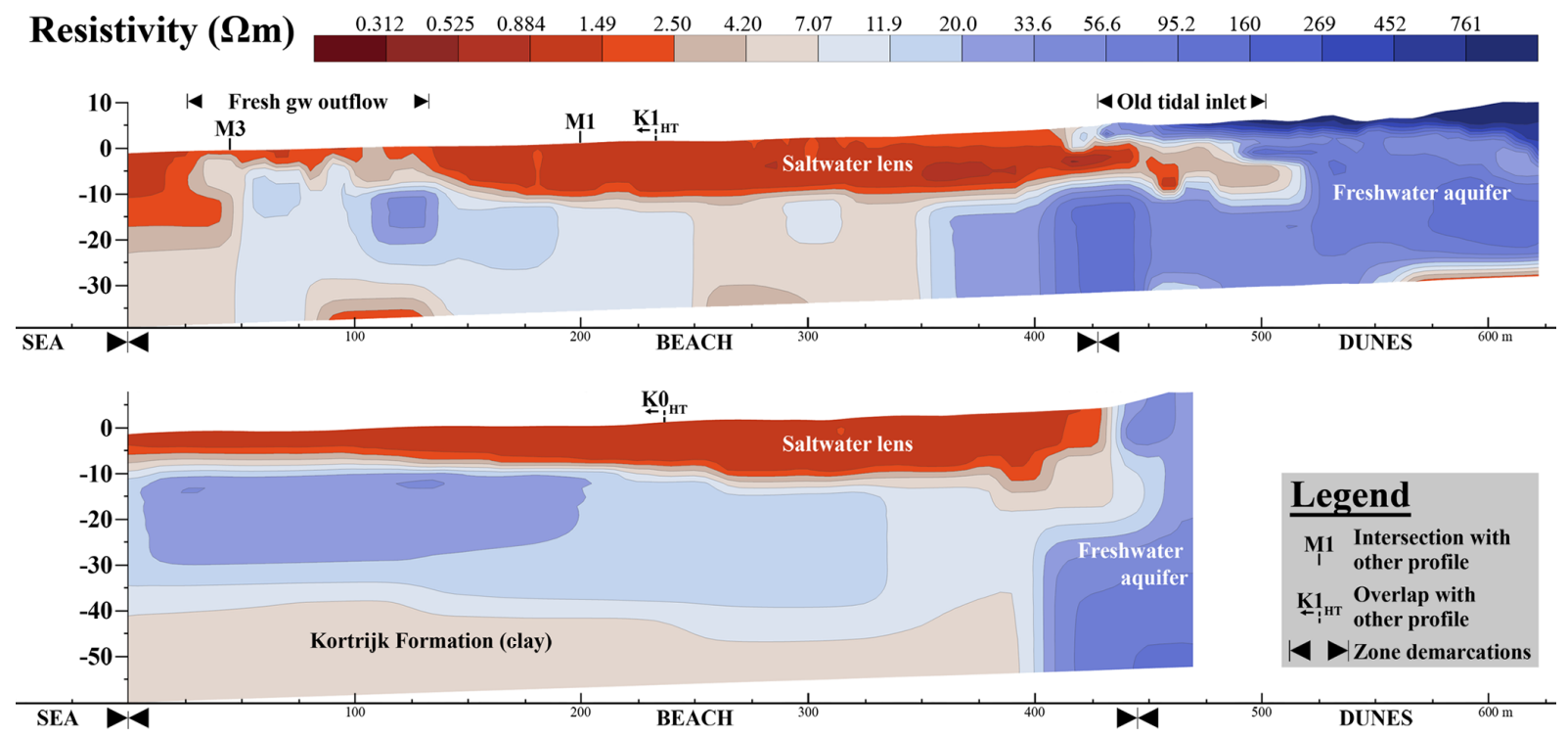

Figure 5. ERT profiles in front of the De Westhoek nature reserve, perpendicular to the beach, at K1 (7 March 2018 ) and K0 (11 October 2018). Profile numbering based on Lebbe (1981), and the water depth is in mTAW (relative to the reference level of Belgium). Groundwater: gw.

system is least affected by anthropogenic effects (extraction facility) in this part of the study area. As a consequence, the pore water is more resistive underneath the beach and further offshore compared to K1.

\subsection{CRP}

The land ERT profiles were extended by marine continuous resistivity profiles collected at high tide, with an overlapping zone of about $230 \mathrm{~m}$ (Fig. 6, $\mathrm{K} 1_{\mathrm{HT}}$ and $\mathrm{K} 0_{\mathrm{HT}}$ ). They confirm the presence of brackish water below the saltwater and indicate that the discharge zone is not limited to the low-water line but that it could extend towards the sea. In the east, weak saltwater migrates towards the seabed around $200 \mathrm{~m}$ in front of the low-water mark (Fig. 6, $\mathrm{K} 1_{\mathrm{HT}}$, light-red colour). Further offshore, a marine profile, collected at low tide (Fig. 6, $\mathrm{K} 1_{\mathrm{LT}}$ ), confirms that brackish pore water can be seen up to at least $550 \mathrm{~m}$ from the low-water line. It is mixed with saltwater in the seabed, making it impossible to visualize FSGD at the top of the seabed using resistivity measurements, but the brackish groundwater is found relatively close to the seabed.

In the west, brackish groundwater is overlain by a thin layer in which pore water is salty (Fig. 6, $\mathrm{K} 0_{\mathrm{HT}}$ ). But the underlying brackish pore water is found closer to the seabed approximately $250 \mathrm{~m}$ offshore the low-water line. The brackish lens (Fig. 6, $\mathrm{K} 0_{\mathrm{LT}}$ ) does not reach as far offshore compared to $\mathrm{K} 1_{\mathrm{LT}}$, perhaps due to different local hydrogeological and geological conditions.

To acquire information on the lateral variation, CRP profiles parallel to the shore were collected during high tide. On the lower beach, the pore water resistivity increases from K1 towards K0 (Fig. 7, M1). This trend is partly due to the thin- ner saltwater lens in the west, which increases the resolution of the inversion model. Modelling studies have shown that the saltwater lens thickness is inversely related to the groundwater flux (Vandenbohede and Lebbe, 2006). Part of the M1 profile (close to the middle) has a thicker lens compared to the zone around $\mathrm{K} 1$, while the water underneath $\mathrm{K} 1$ is more brackish, meaning that the fresh-groundwater flux is lower around $\mathrm{K} 1$. Also closer to the low-water line, resistivity increases from K1 to K0 (Fig. 7, M2). East of K1, a more resistive body (light blue) is seen (Fig. 7, M3), and this is also visible on the raw data. While on the eastern side of the M3 profile (in front of the IWVA site), the resistivity is much lower compared to $\mathrm{K} 1$, which is compatible with a lower fresh-groundwater flux (Vandenbohede and Lebbe, 2006). The higher resistivity between the IWVA and $\mathrm{K} 1$ can have multiple causes, which need further investigation. The thickness of the overlying saltwater lens can have an effect, as well as the width of the beach (which is narrower east of K1). Local hydrogeological heterogeneities can have an influence too, since local clay lenses are present in the phreatic aquifer, which are difficult to identify in a saline environment due to their low resistivity. Maintaining the cable exactly parallel to the beach was also challenging; some measurement distortions are thus also possible.

To confirm the lateral variations in FSGD along this part of the coast, another perpendicular profile was collected further east (Fig. 6, K1.5 $5_{\mathrm{LT}}$ ). Discharge seems stronger on $\mathrm{K} 1_{\mathrm{LT}}$ compared to $\mathrm{K} 1.5_{\mathrm{LT}}$, since the brackish aquifer extends further offshore. This observation is logical; $\mathrm{K} 1.5_{\mathrm{LT}}$ is closer to the IWVA extraction site and, so, more affected by the wa- 


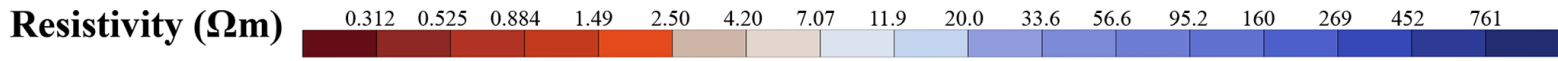
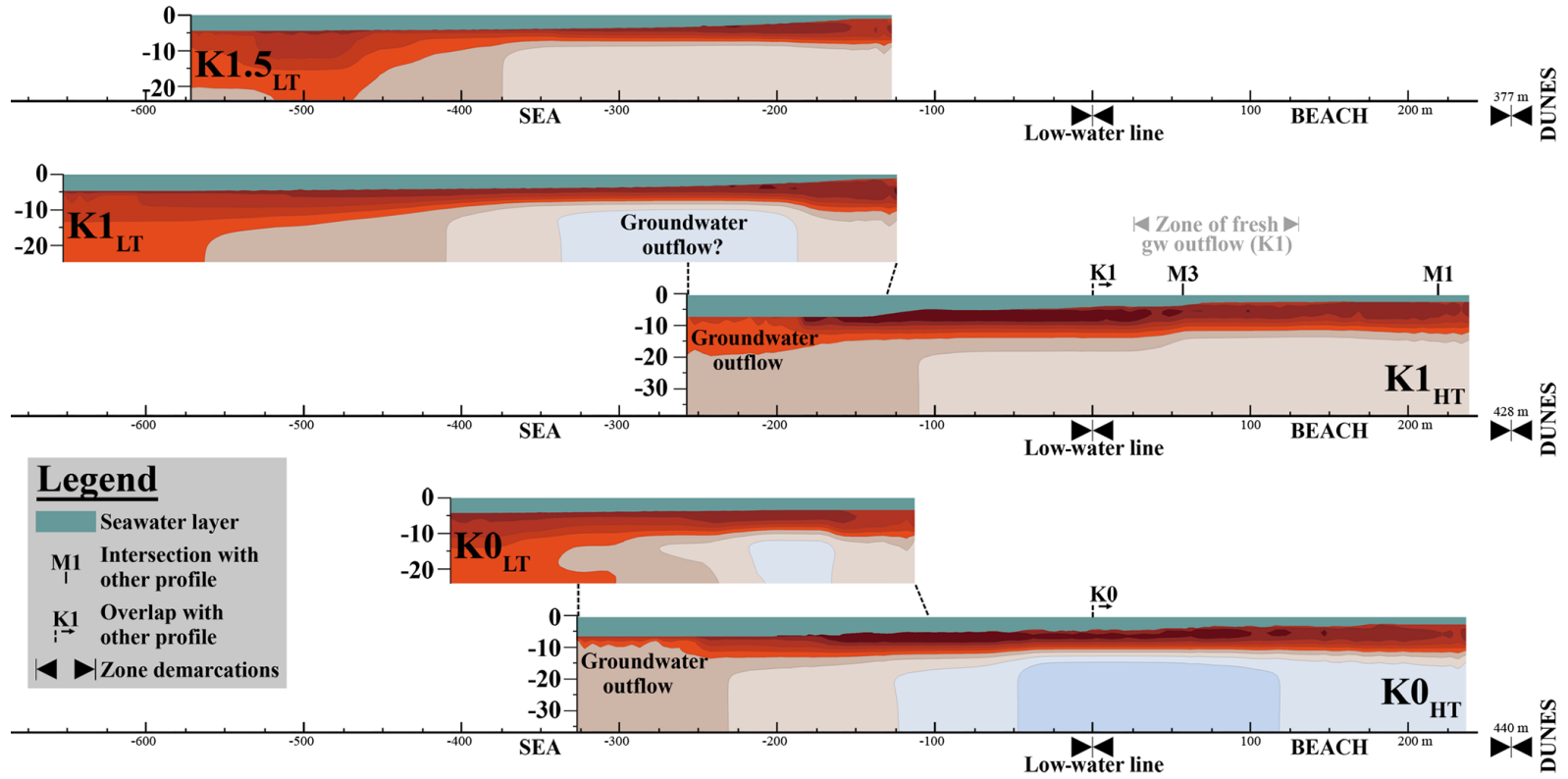

Figure 6. CRP profiles from De Westhoek, perpendicular to the beach, acquired on 30 May 2018 (K1 $1_{\mathrm{HT}}$ and $\left.\mathrm{K} 0_{\mathrm{HT}}\right)$ and $22 \mathrm{May} 2019$ $\left(\mathrm{K} 1.5_{\mathrm{LT}}, \mathrm{K} 1_{\mathrm{LT}}\right.$, and $\left.\mathrm{K} 0_{\mathrm{LT}}\right)$. Profile numbering based on Lebbe (1981), with HT and LT meaning high and low tide, respectively, and water depth in mTAW (relative to the reference level of Belgium). Groundwater: gw.
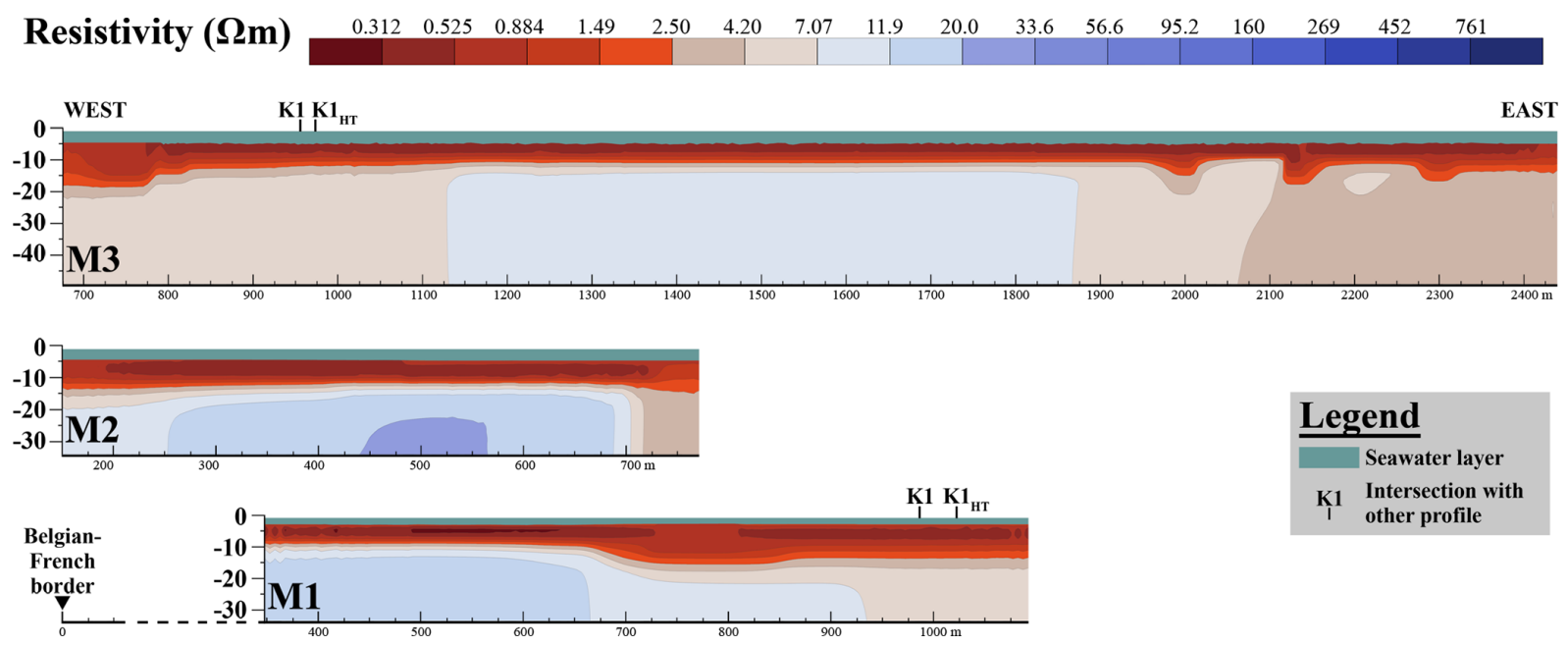

Figure 7. CRP profiles parallel to the beach, taken during high tide (30 May 2018). The water depth in mTAW (relative to the reference level of Belgium).

ter extraction reducing groundwater discharge. However, this should be further examined.

\subsection{Quality appraisal}

The resolution of the high-tide marine profiles is significantly lower compared to that acquired during low tide, since it has a thicker seawater layer above the sea bottom; the portion of saltwater infiltrating in the seabed increases from low to high tide; it is collected in other dynamic conditions (significant groundwater discharge might only occur at low tide, since the hydraulic gradient between land and sea is larger compared to the high tide); the electrodes of the streamer were spaced closer during the low-tide survey (10 $\mathrm{m}$ compared to $15 \mathrm{~m}$ for the high-tide profiles); and fewer channels were obtained in the high-tide survey (due to a bad electrode).

To validate the results of the ERT and CRP inversions, we use the two-sided difference approach and the DOI, additionally computing the inversion for two different refer- 

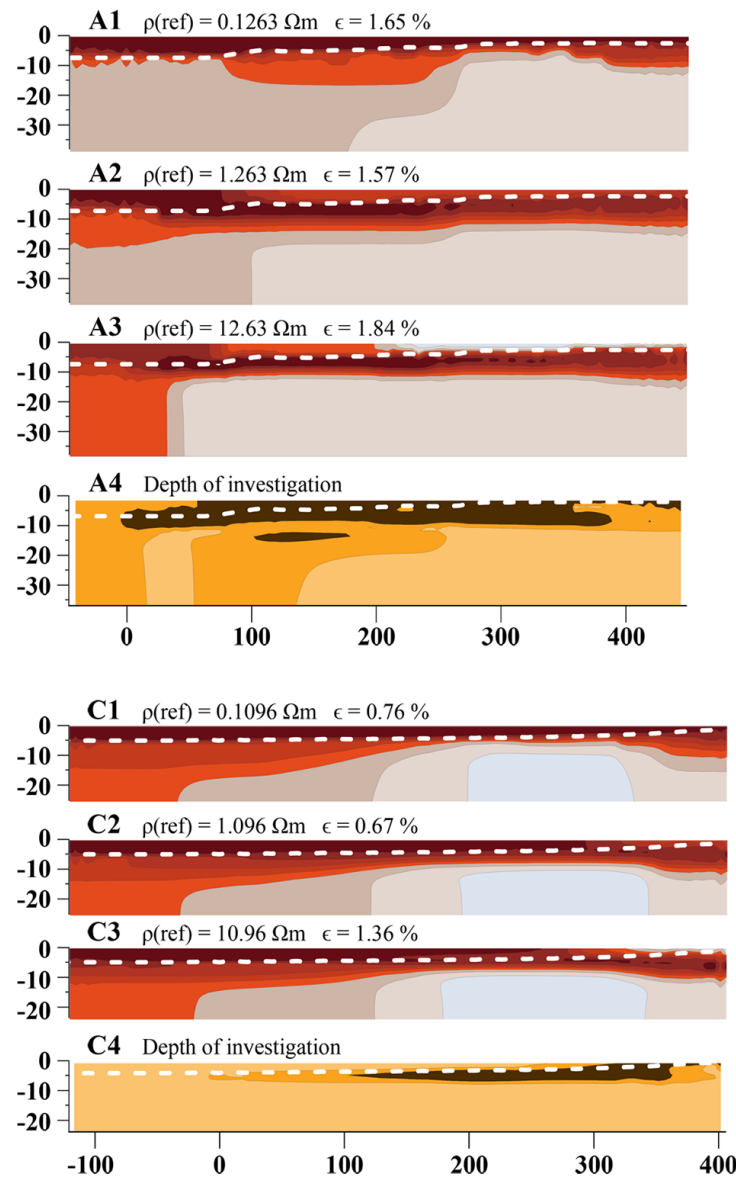
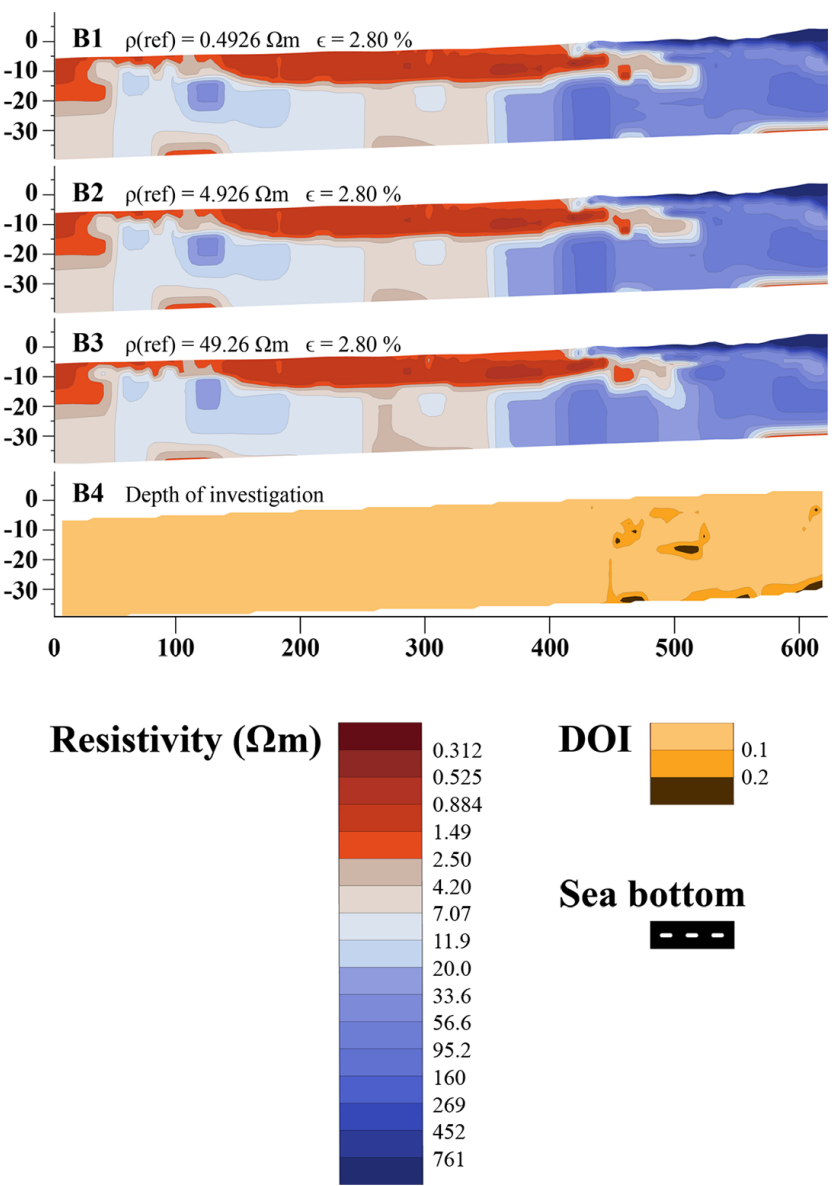

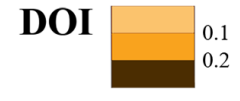

Sea bottom

---

Figure 8. Validation of the inversion models at $1 \mathrm{~km}$ from the Belgian-French border. (A) K1 $1_{\mathrm{HT}}$ marine profile; (B) K1 land ERT profile; (C) $\mathrm{K} 1_{\mathrm{LT}}$ marine profile. HT and LT stand for high and low tide, respectively; $\rho$ (ref) is the reference resistivity; and $\in$ the absolute error.

ence models. We show them for K1 (Fig. 8), but other profiles have similar results. For the land profile, all three inversions (Fig. 8, B1-3) look almost perfectly similar, with practically all DOI values below 0.1 (Fig. 8, B4), indicating that observed structures are qualitatively contained in the data. For the profile at high tide (Fig. 8, A1-3), lateral variations are also similar in the different inversion models, identifying fresher pore water towards the beach. However, small variations are observed vertically around the sea bottom, corresponding to DOI values above 0.2 (Fig. 8, C4), showing that the inversion is particularly sensitive to the bathymetry and the presence of the seawater layer. In this case, a low conductivity reference model will force some more resistive features to appear closer to the sea bottom. As a consequence, brackish pore water seems closer to the sea bottom. Whether this is actually the case or not cannot be elucidated from our measurements, and the true extension of the FSGD zone cannot be delimited with certainty from the high-tide profile. For the low-tide profile (Fig. 8, C1-3), fewer differences are observed compared to those taken during high tide, and the discharge zone is more clearly identified. This is coherent with the higher resolution of the low-tide profile related to the thinner seawater layer. In summary, all profile types, although with different intrinsic resolutions, are sensitive enough to characterize the general salinity distribution in the studied zone.

\subsection{Seasonal variations}

The MiniExplorer and DUALEM data were collected at the end of winter and beginning of autumn, respectively. The FSGD intensity around $\mathrm{K} 1$ is different in February (MiniExplorer) compared to October (DUALEM-421S), but the zone of discharge does not move (Fig. 4). During the former period, the outflow of groundwater is clearly seen around K1 at shallow depth (Fig. 4A), whereas in October, a large zone of salty-brackish pore water is well visible at larger depth (Fig. 4D) but only seen as individual spots of slightly lower conductivity in the shallow subsurface (Fig. 4B and C). According to the modelling results of Vandenbohede and Lebbe (2006), this seems to indicate that FSGD is stronger in winter than autumn. This is likely due to the lower precipitation and higher evaporation and evapotranspiration in summer, lead- 
K1

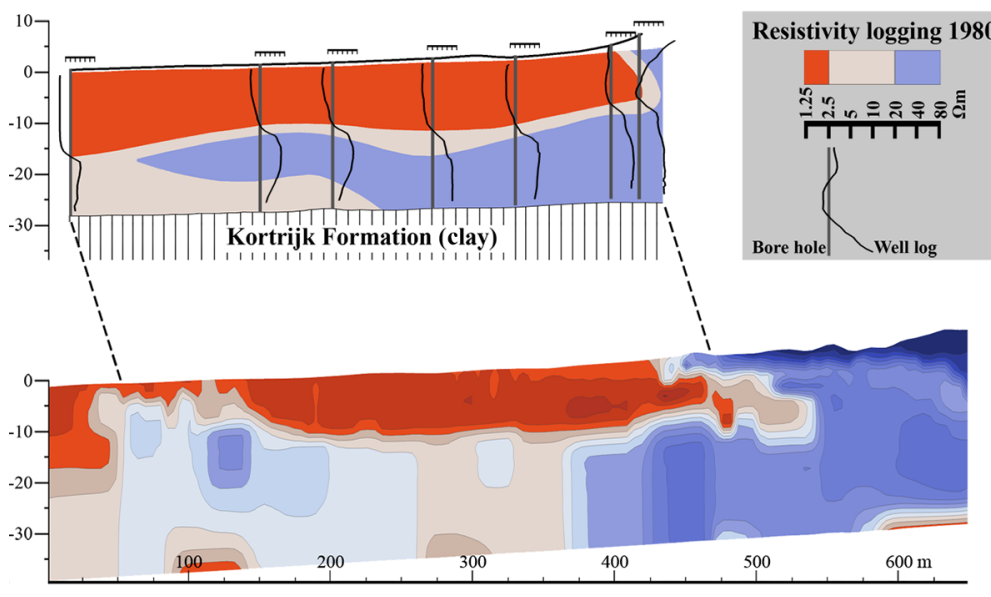

ERT 2018

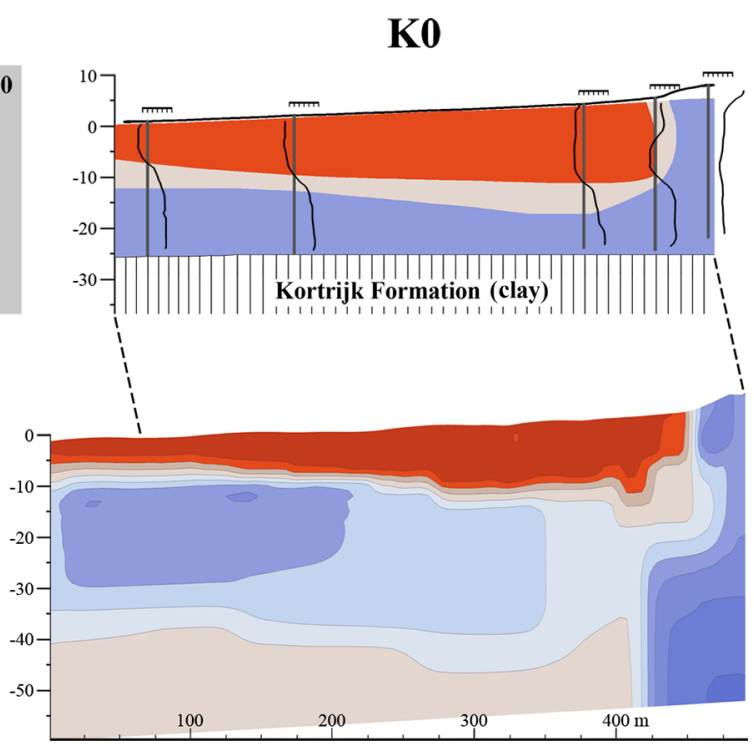

Figure 9. Situation in 1980 versus 2018. Top panels: long normal resistivity logging along K1 and K0, modified from Lebbe (1981). Bottom panels: 2018 land ERT profiles K1 and K0.

ing to smaller groundwater fluxes. In 2018, summer was particularly dry in Belgium.

\subsection{Long-term evolution}

Previous studies had shown the presence of freshwater under the saltwater lens in this study area but could not identify the discharge zone. The identified saltwater lens at $\mathrm{K} 1$ is similar in size to that observed in 1980, based on measurements of well logging on the beach (Lebbe, 1981; Fig. 9, top). However, the lens no longer extends to the sea, since the freshwater tongue reaches the surface nowadays on the lower beach. This is probably an effect of the decreasing pumping trend of the IWVA exploitation site: the rate is now over 4.5 times lower compared to 1980, which has subsequently strengthened the groundwater discharge. Another explanation could be that the logs collected in 1980 were not sufficient to detect the discharge zone, which could have occurred between the two logs closest to the low-water line, in which case the saltwater lens would have remained relatively stable. However, this interpretation does not seem compatible with the newly acquired CRP data which identify the presence of freshwater further offshore. The shape and thickness of the saltwater lens at K0 have not changed much since 1980 (Fig. 9). The lens becomes thinner towards the low-water line, but there is no discharge on the lower beach, since FSGD is located below this level. K0 is located furthest from the IWVA site, and no large extractions are known to occur on the French side of the border, so the effect caused by the decrease of the pumping is more limited.

\subsection{Advantages of the proposed methodology}

By combining ERT, CRP, and FDEM, we have mapped FSGD in 3D over a relatively large area, which comprises the dunes, the upper beach, the intertidal zone, and part of the shelf. FDEM has allowed for imaging the lateral variation of the pore water conductivity in the upper metres of the intertidal zone, while ERT shows the vertical distribution of freshwater and saltwater, which is extended offshore thanks to CRP. Those results could not have been obtained with one of the techniques alone or even with the combination of two of them. The previous conceptual model of the study area (Hermans et al., 2012) can be updated and extended offshore (Fig. 10).

For FDEM, the use of a robust estimation of the apparent conductivity (rECa) is crucial in saline environments. Classical estimations with the LIN approximation would underestimate the ECa and reduce the observed contrasts, likely leading to a wrong interpretation in terms of the salinity and FSGD zone. Using this appropriate correction, we can more easily compare FDEM with ERT, which is crucial in combined geophysical surveys.

It is interesting to note that the presence of fresher water is clearly visible on the raw CRP data as a gradual increase in the apparent resistivity (Fig. 2). The apparent resistivity is the resistivity a homogeneous earth should have to provide with the same potential measurements and the same electrode configuration. It is not only influenced by the aquifer resistivity but also (and mainly) by the low seawater resistivity, explaining why apparent resistivity remains low, even in the presence of freshwater in the aquifer. The apparent resistivity corresponds to a specific combination of four electrodes. With a spacing of 10 or $15 \mathrm{~m}$ between the electrodes, this cor- 


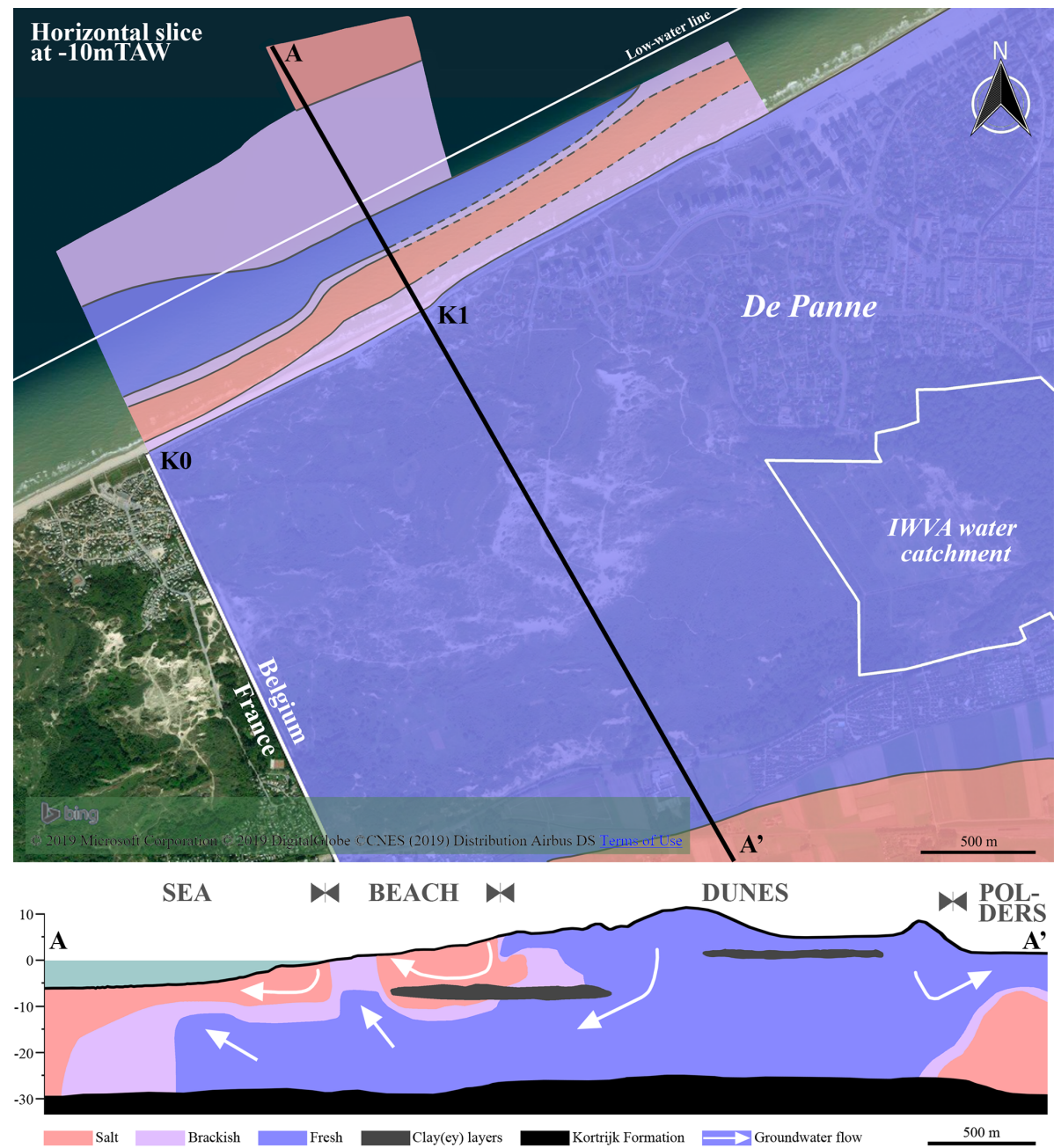

Figure 10. Conceptual model. Based on the data presented in this study of Hermans et al. (2012) and de Verziltingskaart (De Breuck et al., 1974). (C) Microsoft Corporation, DigitalGlobe, and CNES, 2019.

responds to an investigated volume with a minimum of 40 or $60 \mathrm{~m}$ in length. Therefore, the transition caused by changes in the aquifer resistivity will be smoothed by the volume investigated. A sharp freshwater-saltwater interface will thus appear as gradual in the raw data. Yet, possible zones of FSGD can be identified without inversion. If the seawater influence remains constant (which is true as long as its thickness remains similar), an increase of the apparent resistivity must correspond to an increase in the aquifer resistivity and thus a decrease in its salinity. The apparent resistivity will also increase when the bathymetry decreases but to a lesser extent if the aquifer is salty (Fig. 2). CRP can therefore be used as a fast exploration technique to locate zones of brackish-fresh pore water. Using this technique one can easily survey multiple kilometres per day along the coastlines to detect the most vulnerable sites in terms of nutrient or contaminant leakage to the aquatic environment and a loss of freshwater.

\section{Conclusions}

In this contribution, we propose an innovative combination of land ERT and marine CRP together with FDEM mapping to characterize fresh-groundwater discharge. Electrical and electromagnetic methods constitute practical tools in the investigation of FSGD in coastal environments. The very high spatial lateral resolution of FDEM combined with the vertical resolution of ERT allows for interpreting the presence of fresher water in 3D, while minimizing the field effort and the acquisition time. By continuing ERT profiles seaward using CRP, the surveyed area can be extended offshore to identify discharge zones located below the low-water line, even in rough areas characterized by large tidal ranges. While resistivity tomography is used to obtain a general $2 \mathrm{D}$ or pseudo3D model of the saltwater and freshwater distribution on land, in the intertidal zone, and offshore, FDEM mapping provides information on lateral variations. Since the data acquisition is rapid and easy to use, this is perfectly suited for 
the investigation of the intertidal zone and to fill the gap between ERT profiles that take longer to acquire.

As a standard output of commercially available (LIN) FDEM instrumentation systematically underestimates ECa values in highly conductive environments, the technique has, to our knowledge, only rarely been used in the intertidal zone. However, limitations imposed by high conductive environments can be overcome through a more robust interpretation of the collected data (e.g. Hanssens et al., 2019). This further extends the potential of FDEM to characterize FSGD and SI in littoral zones.

We demonstrate the ability of the proposed methodology to characterize freshwater discharge occurring at De Westhoek in the western Belgian coastal plain. In this area, FSGD is present both below sea level and in the intertidal zone. Land ERT profiles clearly identify the saltwater lens, underlain by freshwater and originating from the infiltration of seawater on the low slope shore and discharging on the lower beach. CRP surveys further image the presence of brackish pore water and FSGD offshore. FDEM mapping in the intertidal zone allows for characterizing lateral variations in the discharge zone and locating where it becomes submarine.

To our knowledge, this constitutes the first comprehensive imaging of both the saltwater lens under the beach and the shifting of FSGD seawards using geophysical techniques. The discharge is most visible during low tide, since the fresh-groundwater flux is higher compared to high tide. Lowtide conditions also allow for maximizing the resolution of both land and marine ERT, while enabling the acquisition of FDEM data in the intertidal zone. High-tide data remain necessary to ensure some overlap with land ERT. The groundwater discharge seems to have a seasonal variability, with FSGD being stronger at the end of winter compared to the beginning of autumn, since a warm and dry summer precedes the latter. The comparison of this new dataset to borehole logs from the 1980s shows that the decrease in groundwater pumping in the dunes has strengthened the freshwater outflow in the east of the area.

Data availability. The data are accessible on the Marine Data Archive (https://doi.org/10.14284/414, Paepen et al., 2020).

Supplement. The supplement related to this article is available online at: https://doi.org/10.5194/hess-24-3539-2020-supplement.

Author contributions. MP carried out the field work, processed the resistivity data, performed the literature study, and wrote the first draft. DH and PDS processed the electromagnetic data. TH supervised the study and helped with the field work and the preparation of the draft manuscript. DH, PDS, KW, and TH edited and contributed to the final paper.
Competing interests. The authors declare that they have no conflict of interest.

Acknowledgements. We want to thank the VLIZ for their logistical support in the marine surveys and the University of Liège for lending the land ERT equipment. The authors would also like to acknowledge Josue Chishugi, Nicolas Compaire, Tim Deckmyn, Anja Derycke, Gaël Dumont, Hadrien Michel, Melissa Prieto, Mizanur Rahman Sarker, Robin Thibaut, Bart Van Impe, Valentijn Van Parys, Jan Vermaut, and Nele Vlamynck for their help with the field work. We also thank the editor, Gerrit H. de Rooij, and two anonymous reviewers for their comments which helped to improve this paper.

Financial support. This research has been supported by the Fonds Wetenschappelijk Onderzoek (research credit no. FWO1505219N) and the Brilliant Marine Research Idea Grant 2018 of the Flanders Marine Institute.

Review statement. This paper was edited by Gerrit H. de Rooij and reviewed by two anonymous referees.

\section{References}

Archie, G. E.: The electrical resistivity $\log$ as an aid in determining some reservoir characteristics, T. AIME, 146, 54-62, https://doi.org/10.2118/942054-G, 1942.

Burnett, B., Bokuniewicz, H., Huettel, M., Moore, W. S., and Taniguchi, M.: Groundwater and pore water inputs to the coastal zone, Biogeochemistry, 66, 3-33, https://doi.org/10.1023/B:BIOG.0000006066.21240.53, 2003.

Burnett, W. C. and Dulaiova, H.: Estimating the dynamics of groundwater input into the coastal zone via continuous radon-222 measurements, J. Environ. Radioactiv., 69, 21-35, https://doi.org/10.1016/S0265-931X(03)00084-5, 2003.

Burnett, W. C., Aggarwal, P. K., Aureli, A., Bokuniewicz, H., Cable, J. E., Charette, M. A., Kontar, E., Krupa, S., Kulkarni, K. M., Loveless, A., Moore, W. S., Oberdorfer, J. A., Oliveira, J., Ozyurt, N., Povinec, P., Privitera, A. M. G., Rajar, R., Ramessur, R. T., Scholten, J., Stieglitz, T., Taniguchi, M., and Turner, J. V.: Quantifying submarine groundwater discharge in the coastal zone via multiple methods, Sci. Total Environ., 367, 498-543, https://doi.org/10.1016/j.scitotenv.2006.05.009, 2006.

Callegary, J. B., Ferré, T. P. A., and Groom, R. W.: Vertical Spatial Sensitivity and Exploration Depth of Low-Induction-Number Electromagnetic-Induction Instruments, Vadose Zone J., 6, 158167, https://doi.org/10.2136/vzj2006.0120, 2007.

Cantarero, D. L. M., Blanco, A., Cardenas, M. B., Nadaoka, K., and Siringan, F. P.: Offshore Submarine Groundwater Discharge at a Coral Reef Front Controlled by Faults, Geochem. Geophy. Geosy., 20, 3170-3185, https://doi.org/10.1029/2019GC008310, 2019.

Cardenas, M. B., Zamora, P. B., Siringan, F. P., Lapus, M. R., Rodolfo, R. S., Jacinto, G. S., Diego-McGlone, M. L. S., 
Villanoy, C. L., Cabrera, O., and Senal, M. I.: Linking regional sources and pathways for submarine groundwater discharge at a reef by electrical resistivity tomography, 222Rn, and salinity measurements, Geophys. Res. Lett., 37, L16401, https://doi.org/10.1029/2010GL044066, 2010.

Caterina, D., Beaujean, J., Robert, T., and Nguyen, F.: A comparison study of different image appraisal tools for electrical resistivity tomography, Near Surf. Geophys., 11, 639-657, https://doi.org/10.3997/1873-0604.2013022, 2013.

Caterina, D., Hermans, T., and Nguyen, F.: Case studies of incorporation of prior information in electrical resistivity tomography: comparison of different approaches, Near Surf. Geophys., 12, 451-465, https://doi.org/10.3997/1873-0604.2013070, 2014.

Colman, J. A., Masterson, J. P., Pabich, W. J., and Walter, D. A.: Effects of Aquifer Travel Time on Nitrogen Transport to a Coastal Embayment, Ground Water, 42, 1069-1078, https://doi.org/10.1111/j.1745-6584.2004.tb02644.x, 2004.

Cross, V. A., Bratton, J. F., Bergeron, E. M., Meunier, J. K., Crusius, J., and Koopmans, D.: Continuous resistivity profiling data from the upper Neuse River Estuary, North Carolina, 2004-2005, Open-File Report 2005-1306, US Geological Survey, Virginia, 2006.

Cross, V. A., Bratton, J. F., Crusius, J., Kroeger, K. D., and Worley, C. R.: Continuous resistivity profiling data from Northport Harbor and Manhasset Bay, Long Island, New York, Open-File Report 2011-1041, US Geological Survey, Virginia, https://doi.org/10.3133/ofr20111041, 2012.

Cross, V. A., Bratton, J. F., Kroeger, K. D., Crusius, J., and Worley, C. R.: Continuous resistivity profiling data from Great South Bay, Long Island, New York, Open-File Report 2011-1040, US Geological Survey, Virginia, 2013.

Cross, V. A., Bratton, J. F., Michael, H. A., Kroeger, K. D., Green, A., and Bergeron, E. M.: Continuous resistivity profiling and seismic-reflection data collected in April 2010 from Indian River Bay, Delaware, Open-File Report 2011-1039, US Geological Survey, Virginia, https://doi.org/10.3133/ofr20111039, 2014.

Dahlin, T. and Zhou, B.: A numerical comparison of 2D resistivity imaging with 10 electrode arrays, Geophys. Prospect., 52, 379398, 2004.

Dahlin, T. and Zhou, B.: Multiple-gradient array measurements for multichannel 2D resistivity imaging, Near Surf. Geophys., 4, 113-123, https://doi.org/10.3997/1873-0604.2005037, 2006.

Davies, G., Huang, J., Monteiro Santos, F. A., and Triantafilis, J.: Modeling Coastal Salinity in Quasi 2D and 3D Using a DUALEM-421 and Inversion Software, Groundwater, 53, 424431, https://doi.org/10.1111/gwat.12231, 2015.

Day-Lewis, F. D., White, E. A., Johnson, D., and Lane Jr., J. W.: Continuous resistivity profiling to delineate submarine groundwater discharge - examples and limitations, Leading Edge, 25, 724-728, https://doi.org/10.1190/1.2210056, 2006.

De Breuck, W., De Moor, G., Maréchal, R., and Tavernier, R.: Diepte van het grensvlak tussen zoet en zout water in de freatische laag van het Belgische kustgebied (1963-1773), Verziltingskaart, Militair Geografisch Instituut, Brussel, 1974.

de Franco, E., Biella, G., Tosi, L., Teatini, P., Lozej, A., Chiozzotto, B., Giada, M., Rizzetto, F., Claude, C., Mayer, A., Bassan, V., and Gasparetto-Stori, G.: Monitoring the saltwater intrusion by time lapse electrical resistivity tomography: The Chiog- gia test site (Venice Lagoon, Italy), J. Appl. Geophys., 69, 117130, https://doi.org/10.1016/j.jappgeo.2009.08.004, 2009.

Delefortrie, S., De Smedt, P., Saey, T., Van De Vijver, E., and Van Meirvenne, M.: An efficient calibration procedure for correction of drift in EMI survey data, J. Appl. Geophys., 110, 115125, https://doi.org/10.1016/j.jappgeo.2014.09.004, 2014.

Delefortrie, S., Saey, T., De Pue, J., Van De Vijver, E., De Smedt, P., and Van Meirvenne, M.: Evaluating corrections for a horizontal offset between sensor and position data for surveys on land, Precis. Agricult., 17, 349-364, https://doi.org/10.1007/s11119015-9423-8, 2015.

Delsman, J. R., van Baaren, E. S., Vermaas, T., Karaoulis, M. C., Bootsma, H. P., de Louw, P. G. B., Pauw, P., Oude Essink, G. H. P., Dabekaussen, W., Van Camp, M., Walraevens, K., Vandenbohede, A., Teilmann, R., and Thofte, S.: TOPSOIL Airborne EM kartering van zoet en zout grondwater in Vlaanderen (FRESHEM Vlaanderen): deelopdrachten 1 tot en met 3, report, Deltares, Delft, 111 pp., 2019.

De Moor, G. and De Breuck, W.: De freatische waters in het Oostelijk Kustgebied en de Vlaamse Vallei, Natuurlijk Tijdschrift, 51, 3-68, 1969.

Dimova, N. T., Swarzenski, P. W., Dulaiova, H., and Glenn, C. R.: Utilizing multichannel electrical resistivity methods to examine the dynamics of the fresh water-seawater interface in two Hawaiian groundwater systems, J. Geophys. Res., 117, C02012, https://doi.org/10.1029/2011JC007509, 2012.

Duque, C., Michael, H. A., and Wilson, A. M.: The Subterranean Estuary: Technical Term, Simple Analogy, or Source of Confusion?, Water Resour. Res., 56, e2019WR026554, https://doi.org/10.1029/2019WR026554, 2020.

Evans, R. L., Law, L. K., St. Louis, B., Cheesman, D., and Sananikone, K.: The shallow porosity structure of the Eel shelf, northern California: results of a towed electromagnetic survey, Mar. Geol., 154, 211-226, https://doi.org/10.1016/S00253227(98)00114-5, 1999.

Francés, A. P., Ramalho, E. C., Fernandes, J., Groen, M., Hugman, R., Khalil, M. A., De Plaen, J., and Monteiro Santos, F. A.:Contribution of hydrogeophysics to the hydrogeological conceptual model of the Albufeira-Ribeira de Quarteira coastal aquifer in Algarve, Portugal, Hydrogeol. J., 23, 1553-1572, https://doi.org/10.1007/s10040-015-1282-x, 2015.

Goebel, M., Pidlisecky, A., and Knight, R.: Resistivity imaging reveals complex pattern of saltwater intrusion along Monterey coast, J. Hydrol., 551, 746-755, https://doi.org/10.1016/j.jhydrol.2017.02.037, 2017.

Goebel, M., Knight, R., and Halkjær, M.: Mapping saltwater intrusion with an airborne electromagnetic method in the offshore coastal environment, Monterey Bay, California, J. Hydrol.: Reg. Stud., 23, 100602, https://doi.org/10.1016/j.ejrh.2019.100602, 2019.

Goldman, M., Gilad, D., Ronen, A., and Melloul, A.: Mapping of seawater intrusion into the coastal aquifer of Israel by the time domain electromagnetic method, Geoexploration, 28, 153-174, https://doi.org/10.1016/0016-7142(91)90046-F, 1991.

Goldman, M., Gvirtzman, H., and Hurwitz, S.: Mapping saline groundwater beneath the Sea Galilee and its vicinity using time domain electromagnetic (TDEM) geophysical technique, Israel J. Earth Sci., 53, 187-197, https://doi.org/10.1560/P1W7UYDE-WJFW-CVHB, 2004. 
Greenwood, W. J., Kruse, S., and Swarzenski, P.: Extending Electromagnetic Methods to Map Coastal Pore Water Salinities, Groundwater, 44, 292-299, https://doi.org/10.1111/j.17456584.2005.00137.x, 2006.

Hanssens, D., Delefortrie, S., Bobe, C., Hermans, T., and De Smedt, P.: Improving the reliability of soil EC-mapping: Robust apparent electrical conductivity (rECa) estimation in ground-based frequency domain electromagnetics, Geoderma, 337, 1155-1163, https://doi.org/10.1016/j.geoderma.2018.11.030, 2019.

Henderson, R. D., Day-Lewis, F. D., Abarca, E., Harvey, C. F., Karam, H. N., Liu, L., and Lane Jr., J. W.: Marine electrical resistivity imaging of submarine groundwater discharge: sensitivity analysis and application in Waquoit Bay, Massachusetts, USA, Hydrogeol. J., 18, 178-185, https://doi.org/10.1007/s10040-0090498-z, 2010.

Hermans, T. and Paepen, M.: Combined inversion of land and marine electrical resistivity tomography for submarine groundwater discharge and saltwater intrusion characterization, Geophys. Res. Lett., 47, e2019GL085877, https://doi.org/10.1029/2019GL085877, 2020.

Hermans, T., Vandenbohede, A., Lebbe, L., Martin, R., Kemna, A., Beaujean, J., and Nguyen, F.: Imaging artificial salt water infiltration using electrical resitistivity tomography constrained by geostatistical data, J. Hydrol., 438-439, 168-180, https://doi.org/10.1016/j.jhydrol.2012.03.021, 2012.

Hoefel, F. G. and Evans, R. L.: Impact of Low Salinity Porewater on Seafloor Electromagnetic Data: A Means of Detecting Submarine Groundwater Discharge?, Estuar. Coast. Shelf Sci., 52, 179-189, https://doi.org/10.1006/ecss.2000.0718, 2001.

Kinnear, J. A., Binley, A., Duque, C., and Engesgaard, P. K.: Using geophysics to map areas of potential groundwater discharge into Ringkøbing Fjord, Denmark, Leading Edge, 32, 792-796, https://doi.org/10.1190/tle32070792.1, 2013.

Krantz, D. E., Manheim, F. T., Bratton, J. F., and Phelan, D. J.: Hydrogeologic Setting and Ground Water Flow Beneath a Section of Indian River Bay, Delaware, Groundwater, 42, 1035-1051, https://doi.org/10.1111/j.1745-6584.2004.tb02642.x, 2004.

Lapointe, B. E., Barile, P. J., Littler, M. M., and Littler, D. S.: Macroalgal blooms on southeast Florida coral reefs II. Crossshelf discrimination of nitrogen sources indicates widespread assimilation of sewage nitrogen, Harmful Algae, 4, 1103-1122, https://doi.org/10.1016/j.hal.2005.06.002, 2005.

Lebbe, L.: Hydrogeologie van het duingebied ten westen van De Panne, PhD thesis, Ghent University, Belgium, 164 pp., 1978.

Lebbe, L.: The subterranean flow of fresh and salt water underneath the Western Belgian beach, in: Proceedings of the 7th Salt Water Intrusion Meeting, Uppsala, Sweden, 193-219, 1981.

Lebbe, L.: Mathematical model of the evolution of the fresh water lens under the dunes and beach with semi-diurnal tides, Geologia applicata e idrogeologia, 18, 211-226, 1983.

Lebbe, L.: Numerische simulatie van grondwaterkwaliteitsproblemen als hulp bij het beheer van de watervoorraden in het Vlaamse kustgebied, Tijdschrift BECEWA, 76, 67-88, 1984.

Lebbe, L.: Parameter identifcation in fresh-saltwater flow based on borehole resistivities and freshwater head data, Adv. Water Resour., 22, 791-806, https://doi.org/10.1016/S03091708(98)00054-2, 1999.

Lebbe, L. and Walraevens, K.: Hydrogeological SWIM-excursion to the western coastal plain of Belgium, in: Proceedings of the 10th Salt Water Intrusion Meeting, 16-20 May 1988, Ghent, Belgium, 359-375, 1988.

Loke, M. H.: RES2DINV ver. 3.71. Rapid 2-D resistivity \& IP inversion using the least squares method, available at: https://www. geotomosoft.com/downloads.php (last access: 3 July 2018), 2011.

McNeill, J. D.: Electromagnetic terrain conductivity measurement at low induction numbers, Technical Note, Geonics, Canada, 15 pp., 1980.

Michael, H. A., Mulligan, A. E., and Harvey, C. F.: Seasonal oscillations in water exchange between aquifers and the coastal ocean, Nature, 436, 1145-1148, https://doi.org/10.1038/nature03935, 2005.

Moore, W. S.: The Effect of Submarine Groundwater Discharge on the Ocean, Annu. Rev. Mar. Sci., 2, 59-88, https://doi.org/10.1146/annurev-marine-120308-081019, 2010.

Obikoya, I. B. and Bennell, J. D.: Geophysical Investigation of the Fresh-Saline Water Interface in the Coastal Area of Abergwyngregyn, J. Environ. Protect., 3, 1039-1046, https://doi.org/10.4236/jep.2012.39121, 2012.

Ogilvy, R. D., Meldrum, P. I., Wilkinson, P. B., Chambers, J. E., Sen, M., Pulido-Bosch, A., Gisbert, J., Jorreto, S., Frances, I., and Tsourlos, P.: Automated monitoring of coastal aquifers with electrical resistivity tomography, Near Surf. Geophys., 7, 367376, https://doi.org/10.3997/1873-0604.2009027, 2009.

Oldenburg, D. W. and Li, Y.: Estimating depth of investigation in dc resistivity and IP surveys, Geophysics, 64, 403-416, https://doi.org/10.1190/1.1444545, 1999.

Paepen, M., Hanssens, D., De Smedt, P., Walraevens, K., and Hermans, T.: Combining resistivity and frequency domain electromagnetic methods to investigate submarine groundwater discharge (SGD) in the littoral zone, Marine Data Archive, https://doi.org/10.14284/414, 2020.

Paine, J.: Determining salinization extent, identifying salinity sources, and estimating chloride mass using surface, borehole, and airborne electromagnetic induction methods, Water Resour. Res., 39, 1059, https://doi.org/10.1029/2001WR000710, 2003.

Palacios, A., Ledo, J. J., Linde, N., Luquot, L., Bellmunt, F., Folch, A., Marcuello, A., Queralt, P., Pezard, P. A., Martínez, L., Bosch, D., and Carrera, J.: Time-lapse cross-hole electrical resistivity tomography (CHERT) for monitoring seawater intrusion dynamics in a Mediterranean aquifer, Hydrol. Earth Syst. Sci., 24, 21212139, https://doi.org/10.5194/hess-24-2121-2020, 2020.

Pauw, P. S.: The onshore and offshore groundwater salinity distribution between Egmondd aan Zee and Castricum aan Zee, MS thesis, Vrije Universiteit, Amsterdam, the Netherlands, 53 pp., 2009.

Rodellas, V., Stieglitz, T. C., Andrisoa, A., Cook, P. G., Raimbault, P., Tamborski, J. J., and Radakovitch, O.: Groundwater-driven nutrient inputs to coastal lagoons: The relevance of lagoon water recirculation as a conveyor of dissolved nutrients, Sci. Total Environ., 642, 764-780, https://doi.org/10.1016/j.scitotenv.2018.06.095, 2018.

Russoniello, C. J., Fernandez, C., Bratton, J. F., Banaszak, J. F., Krantz, D. E., Andres, A. S., Konikow, L. F., and Michael, H. A.: Geologic effects on groundwater salinity and discharge into an estuary, J. Hydrol., 498, 1-12, https://doi.org/10.1016/j.jhydrol.2013.05.049, 2013.

Siemon, B., Christiansen, A. V., and Auken, E.: A review of helicopter-borne electromagnetic methods for ground- 
water exploration, Near Surf. Geophys., 7, 629-646, https://doi.org/10.3997/1873-0604.2009043, 2009.

Swarzenski, P. W. and Izbicki, J. A.: Coastal groundwater dynamics off Santa Barbara, California: Combining geochemical tracers, electromagnetic seepmeters, and electrical resistivity, Estuar. Coast. Shelf Sci., 83, 77-89, https://doi.org/10.1016/j.ecss.2009.03.027, 2009.

Swarzenski, P. W., Burnett, B., Reich, C., Dulaiova, H., Peterson, R., and Meunier, J.: Novel geophysical and geochemical techniques used to study submarine groundwater discharge in Biscayne Bay, Florida, Fact Sheet 3117, US Geological Survey, Virginia, 2004.

Swarzenski, P. W., Burnett, W. C., Greenwood, W. J., Herut, B., Peterson, R., Dimova, N., Shalem, Y., Yechieli, Y., and Weinstein, Y.: Combined time-series resistivity and geochemical tracer techniques to examine submarine groundwater discharge at Dor Beach, Israel, Geophys. Res. Lett., 33, L24405, https://doi.org/10.1029/2006GL028282, 2006.

Swarzenski, P. W., Reich, C., and Rudnick, D.: Examining Submarine Ground-Water Discharge into Florida Bay by using ${ }^{222} \mathrm{Rn}$ and Continuous Resistivity Profiling, Open-File Report 20081342, US Geological Survey, Virginia, 2009.

Taniguchi, M., Burnett, W. C., Cable, J. E., and Turner, J. V.: Investigation of submarine groundwater discharge, Hydrol. Process., 16, 2115-2129, https://doi.org/10.1002/hyp.1145, 2002.

Taniguchi, M., Ishitobi, T., Burnett, W. C., and Wattayakorn, G.: Evaluating Ground Water-Sea Water Interactions via Resistivity and Seepage Meters, Groundwater, 45, 729-735, https://doi.org/10.1111/j.1745-6584.2007.00343.x, 2007.

Taniguchi, M., Dulai, H., Burnett, K. M., Santos, I. R., Sugimoto, R., Stieglitz, T., Kim, G., Moosdorf, N., and Burnett, W. C.: Submarine Groundwater Discharge: Updates on Its Measurement Techniques, Geophysical Drivers, Magnitudes, and Effects, Front. Environ. Sci., 7, 1-26, https://doi.org/10.3389/fenvs.2019.00141, 2019.
Van Camp, M. and Walraevens, K.: Direct groundwater discharge to the North Sea. A case study for the Western Belgian coast, in: Proceedings of the 18th Salt Water Intrusion Meeting, 31 May3 June 2004, Cartagena, Spain, 139-150, 2004.

Vandenbohede, A. and Lebbe, L.: Occurrence of salt water above fresh water in dynamic equilibrium in a coastal groundwater flow system near De Panne, Belgium, Hydrogeol. J., 14, 462-472, https://doi.org/10.1007/s10040-005-0446-5, 2006.

Vandenbohede, A. and Lebbe, L.: Effects of tides on a sloping shore: groundwater dynamics and propagation of the tidal wave, Hydrogeol. J., 15, 645-658, https://doi.org/10.1007/s10040-0060128-y, 2007.

Vandenbohede, A. and Lebbe, L.: Heat transport in a coastal groundwater flow system near De Panne, Belgium, Hydrogeol J., 19, 1225-1238, https://doi.org/10.1007/s10040-011-0756-8, 2011.

Vandenbohede, A., Luyten, K., and Lebbe, L.: Effects of Global Change on Heterogeneous Coastal Aquifers: A Case Study in Belgium, J. Coast. Res., 24, 160-170, https://doi.org/10.2112/05-0447.1, 2008a.

Vandenbohede, A., Lebbe, L., Gysens, S., Delecluyse, K., and DeWolf, P.: Salt water infiltrations in two artificial inlets in the Belgian dunes area, J. Hydrogeol., 360, 77-86, https://doi.org/10.1016/j.jhydrol.2008.07.018, 2008b.

Viezzoli, A., Tosi, L., Teatini, P., and Silvestri, S.: Surface water-groundwater exchange in transitional coastal environments by airborne electromagnetics: The Venice Lagoon example, Geophys. Res. Lett., 37, L01402, https://doi.org/10.1029/2009GL041572, 2010.

Viezzoli, A., Munday, T., and Cooper, Y. L.: Airborne electromagnetics for groundwater salinity mapping: case studies of coastal and inland salinisation from around the world, Bollettino di Geofisica Teorica ed Applicata, 53, 581-600, https://doi.org/10.4430/bgta0067, 2012. 